Final Technical Report

Project Title:

Melting Efficiency Improvement

Award Number: DE-FC36-04GO14230

Project Period: (January 2004 - June 2012)

Principal Investigator:

Kent Peaslee, 573-341-4714, kpeaslee@ mst.edu

Co-PI's: Von Richards (vonlr@ mst.edu)

Jeffrey Smith (jsmith@mst.edu)

Recipient Organization:

Missouri University of Science and Technology

Office of Sponsored Programs

202 Centennial Hall, 300 W. 12th St.

Rolla, MO 65409-1330

Subtask Participants (cost sharing):

American Cast Iron Pipe Company

American Centrifugal

Atlas Castings

Bahr Bros. Mfg., Inc.

Magotteaux

Pacific Steel Casting Company

Richmond Foundry Co.

Southern Alloy Corporation

Spokane Industries

Stainless Foundry \& Engineering, Inc.

Steel Founders' Society of America

July 31, 2012 


\section{Acknowledgment and Disclaimer:}

Acknowledgement: This report is based upon work supported by the U.S. Department of Energy under Award No DE-FC36-04GO14230.

Disclaimer: Any findings, opinions, and conclusions or recommendations expressed in this report are those of the authors and do not necessarily reflect the views of the Department of Energy.

Proprietary Data Notice: None in report. 


\section{Table of Contents}

Table of Contents ...............................................................................................................

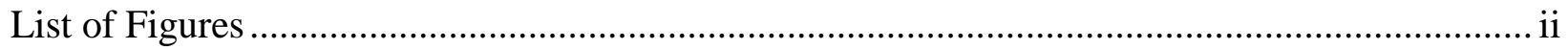

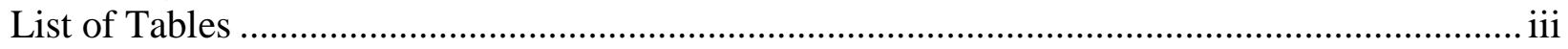

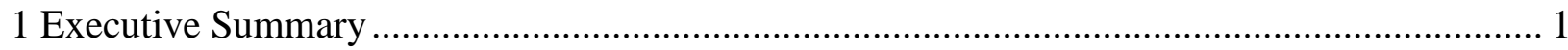

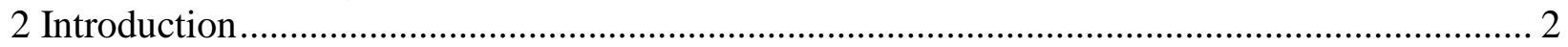

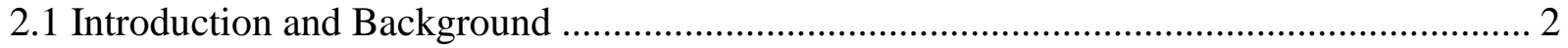

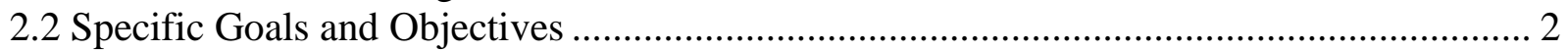

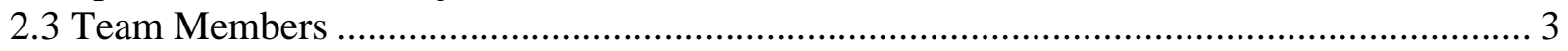

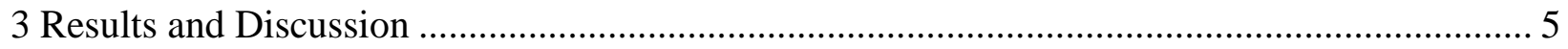

3.1 TASKS 1 - Research wrought industry energy usage and TASK 2 Research steel casting industry energy usage ................................................................................................ 5

3.1.1 - Alloy recovery and control in steel foundry melting ........................................... 5

3.1.2 - Benchmarking of Steel Foundry Industry ........................................................... 5

3.1.2 - Benchmarking of Steel Foundry Industry ……....................................................... 7

3.2 TASK 3 - Determine opportunities for technical transfer - wrought to steel casting .......... 9

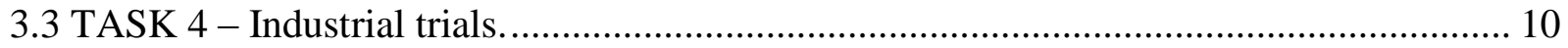

3.3.1 - Induction Furnace Studies - Improved Scheduling ................................................ 10

3.3.2 - Induction Furnace Trials - Alloy Control.............................................................. 13

3.3.3 - Electric Furnace Trials - Chemical Energy - SiC .................................................... 14

3.3.4 - Electric Furnace Trials - Chemical Energy - Oxy-Fuel and Co-Jet Trials ............... 17

3.3.5 - Industrial Ladle Trials Using Lightweight Low Thermal Conductivity Lining ........ 19

3.4 TASK 5 - Laboratory study of factors affecting energy consumption during melting in

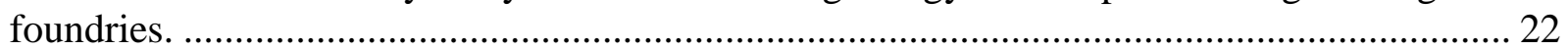

3.4.1 - New refractory applications to reduce ladle losses................................................. 22

3.5 TASK 6 - Energy model of steel foundry melting operations............................................ 29

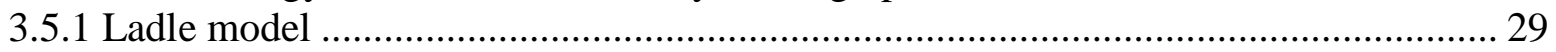

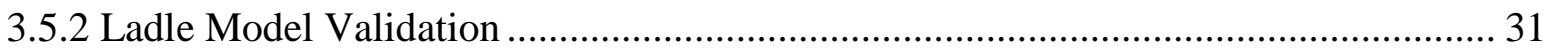

3.5.3 Excel-based calculator for ladles .............................................................................. 31

3.5.4 Development of model of energy use during melting in induction furnaces................ 32

3.5.5 Excel-based electrical energy consumption calculator/optimizer................................ 35

3.5.6 Validation of the induction furnace spreadsheet calculator ......................................... 36

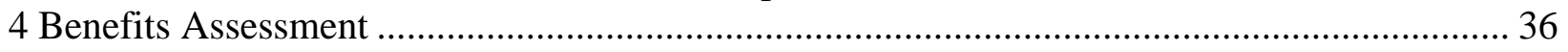

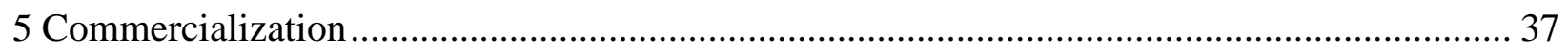

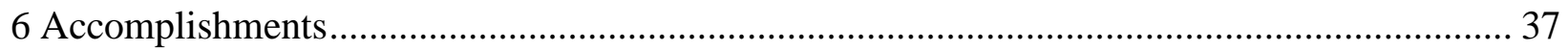

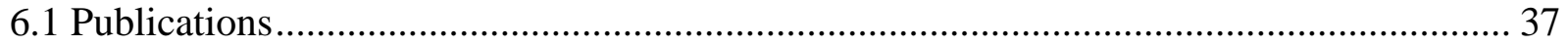

6.2 Graduate students thesis based on the project work ……….............................................. 38

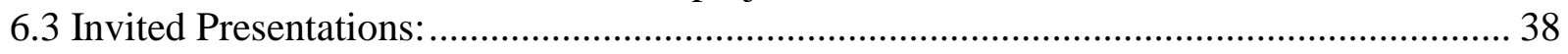

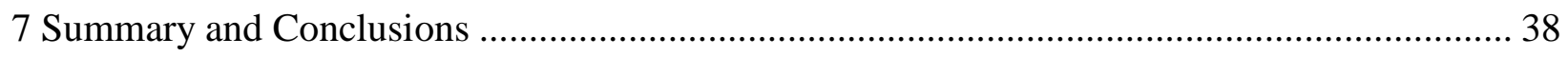

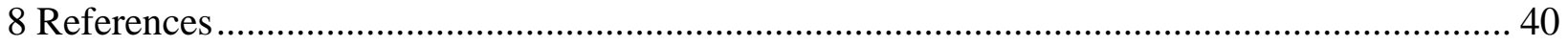

Appendix 1: Assumptions for Calculating Energy Savings .................................................... 42 


\section{List of Figures}

Figure 1 Reduction in alloy use through controlled alloying in steel foundries 5

Figure 2 Variation of manganese concentration in steel melted in different foundries $\quad 7$

Figure 3 Electrical energy consumption comparison for steel foundries 9

Figure 4 Modified Sankey-diagrams (energy flow) for first heats on a lining 12

Figure 5 Modified Sankey-diagrams (energy flow) of heats in hot lining with $200 \mathrm{lb}$ heel 12

Figure 6 Melting energy efficiency before (2004) and after (2005) process improvements 13

Figure 7 Mn variation in WCB product before (2004) and after (2005) practice changes 14

Figure 8 Chemical energy in the steel, slag and above the bath of the EAF 15

Figure 9 Comparison of electrical energy consumption for melting with SiC (Foundry A) 16

Figure 10 Comparison of electrical energy consumption for melting with SiC (Foundry B) 16

Figure 11 Energy use and losses in an EAF (a) during melting and (b) flat bath 17

Figure 12 Total and operational energy efficiency for heats with and without $\mathrm{SiC} \quad 18$

Figure 13 Electrical energy use (in kWh/ton) with oxy-fuel burner/Co-Jet in 20t EAF 18

Figure 14 Total heat time (in min) for a 20t basic EAF with oxy-fuel/Co-Jet 19

Figure 15 Thermal conductivity and density of lining materials 20

Figure 16 a) Insulation lining inside the steel shell b) ladle with cast commercial lining 21

Figure 17 Steel temperature in castable alumina ladle and sandwich lining during holding 22

Figure 18 Distribution of a) steel foundry ladle size and b) lining surface/melt weight ratio 23

Figure 19 Effect of ladle capacity on a) tap temperature and b) rate of temperature loss 23

Figure 20 a) Influence of ladle capacity on temperature losses during holding and b) temperature loss by lining accumulation and radiation from top surface of $5000 \mathrm{lb}$ ladle 24

\section{Figure 21}

21

Figure 22 SEM images of a foamed insulating castable fracture surface 25

Figure 23 a) Standard alumina castable, b) low-density magnesia and c) new alumina castable 26

Figure 24 a) Insert with thermocouples and b) ladle with insert and thermocouples 26

Figure 25 Effect of a) lining temperature and b) lining density on lining thermal conductivity 27

Figure 26 Comparison of melt temperature losses in the ladle with different linings 28

Figure 27 Required tap temperatures for pour temperature of $2840 \mathrm{~F}$ at 12 minutes after tap in $1000 \mathrm{lb}$ ladles lined with different refractories (FLUENT model) 29

Figure 28 Heat losses from ladle during tapping and holding steel 30

Figure 29 Heat flux from inside of a 20 ton and 1 ton ladle lining: a) - no preheated with $\mathrm{k}=1.5$ $\mathrm{W} / \mathrm{m}-\mathrm{K}$ and $\mathrm{b})$ - preheated at $1200^{\circ} \mathrm{C}(2192 \mathrm{~F})$ for 2 hours with $\mathrm{k}=3 \mathrm{~W} / \mathrm{m}-\mathrm{K}$

Figure 30 Validation of model by comparing predictions with industrial trials 31

Figure 31 Interface of spreadsheet for calculating (a) temperature losses in ladle and (b) predicted temperature drop under different scenarios. Holding for 15 minutes in a 20 ton ladle lined with alumina refractory $(\mathrm{k}=1.5 \mathrm{~W} / \mathrm{m}-\mathrm{K})$ preheated to $1800 \mathrm{~F}$

Figure 32 Heat fluxes considered in model of steel melting induction furnace 33

Figure 33 Temperature of lining during three periods of melting steel in induction furnace 33

Figure 34 Temperature of IF lining between heats - Fluent model and regression analysis 34

Figure 35 Illustration of effects of melting practice on process time and energy consumption 35

Figure 36 Interface of spreadsheet calculator for IF energy consumption 35

Figure 37 Validation of model with induction furnace electrical energy consumption data 36 


\section{List of Tables}

Table 1 Recovery and variation of $M n$ in different foundries and wrought industry (LMF)........ 7

Table 2 Comparison of energy (min-ave- max) for EAFs in foundries and mini-mills............. 9

Table 3 Comparison of heats before and after process changes ........................................... 12

Table 4 Comparison of final $M n$ before (2004) and after (2005) process changes.................... 13

Table 5 Effect of $\mathrm{SiC}$ additions on energy consumption and productivity (Foundry A) ............ 15

Table 6 Effect of $\mathrm{SiC}$ additions on energy consumption and productivity (Foundry B) ............. 16

Table 7 Electrical energy consumption in 20t basic EAF with oxy-fuel burner and Co-Jet........ 18

Table 8 Statistics for total heat time (in minutes) for 20t basic EAF with oxy-fuel/Co-Jet........ 19

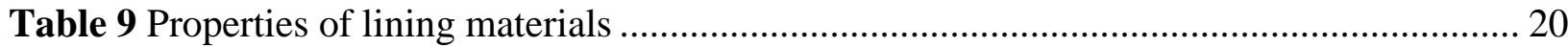

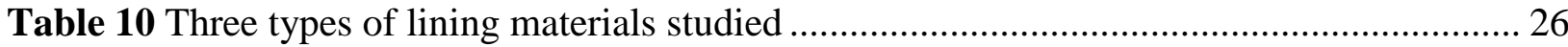

Table 11 Ladle holding time for melt temperature to drop from $1600^{\circ} \mathrm{C}$ to $1350^{\circ} \mathrm{C} \ldots \ldots \ldots \ldots \ldots . . . . . .27$

Table 12 List of industrial cases used for model validation................................................... 31

Table 13 Comparing industrial results and induction furnace model - best practice optimization 


\section{Executive Summary}

Steel foundries melt recycled scrap in electric furnaces and typically consume $35-100 \%$ excess energy from the theoretical energy requirement required to pour metal castings. This excess melting energy is multiplied by yield losses during casting and finishing operations resulting in the embodied energy in a cast product typically being three to six times the theoretical energy requirement. The purpose of this research project was to study steel foundry melting operations to understand energy use and requirements for casting operations, define variations in energy consumption, determine technologies and practices that are successful in reducing melting energy and develop new melting techniques and tools to improve the energy efficiency of melting in steel foundry operations.

Early in the research project, a comprehensive benchmarking study of the variability in melting practices and the associated energy losses was completed. This study showed that there was significant variation in the energy use between the foundries studied which revealed opportunities for improvements in energy efficiency of all steel foundries. This research concentrated on the effects of improved production scheduling, use of technologies to reduce radiation and conduction losses during melting and holding, introduction of supplemental energy to reduce electrical energy and energy losses during production, and development of evaluation tools for the industry to estimate the implementation of future melting improvements.

Specifically, this research project demonstrated through laboratory experiments and industrial plant trials energy benefits of: improved production schedules (5-15\% improvement in electrical energy consumed during melting from reduced start-up losses on cold furnaces and more efficient use of hot furnaces), more efficient use of alloys (20\% total alloy savings from lower aim chemistries and reduced chemistry variability), reduced radiation losses (5\% electrical energy savings during melting from furnace and ladle covers), chemical energy additions to the melting furnace (5-20\% electrical energy savings during melting from oxygen, oxy-fuel, and silicon carbide), and ladle improvements (3-5\% electrical energy savings through reduced tap temperatures from preheating and improved ladle materials). In addition, new calculation tools were developed for foundries to evaluate the potential energy benefits of practice improvements (induction furnace and ladle).

Near the end of the project, a second benchmarking study was completed which showed the improvements that had occurred in melting energy efficiency during the period of this research. The steel foundries participating in this study reported that they are now using an average of $7 \%$ less energy today than at the beginning of the project with approximately $50 \%$ of the foundries implementing at least part of the energy savings practices recommended by this project. If $100 \%$ of the foundries had implemented at least some of the recommendations from this project, it is estimated that the average savings would be double or approximately $15 \%$, the original goal of the project. The electrical energy savings were calculated per melted ton of steel. Because yield losses are typically 35-60\% in most steel foundries, energy savings would be even more significant if calculated per product ton. Current (2012) annual energy saving estimates, based on dissemination to the casting industry in 2012 and market penetration of $90 \%$ by 2022, is 2.7 trillion BTU's/year. 


\section{Introduction}

\subsection{Introduction and Background}

According to a DOE-OIT study completed in 2000 on energy use in the U.S. steel industry, the wrought steel industry has reduced its energy consumption per shipped ton by $60 \%$ during the last 50 years. ${ }^{1}$ The major improvements in energy consumption are a result of better equipment, improved melting and casting practices, and increased use of new technologies such as process/computer controls in the melting/casting operations. In contrast, a barrier to energy improvement in the metal casting industry has been a lack of major changes to their melting equipment, practices, and technologies. Therefore, the steel foundry industry has not experienced the improvements in energy achieved by the wrought industry. The theoretical amount of electrical energy required to melt steel and heat it to a tap temperature of $3000^{\circ} \mathrm{F}\left(1649^{\circ} \mathrm{C}\right)$ is 350 $\mathrm{kWh} /$ ton. Most steel foundries consume $500-800 \mathrm{kWh} / \mathrm{ton}$ in melting, 35-100\% in excess of the theoretical electrical energy requirement. Energy losses during melting are multiplied by yield losses during casting and finishing which can often be as high as $50 \%$. When including the energy losses during melting and casting operations, electrical energy used by steel foundries can be three to six times the theoretical energy requirement. Thus, the opportunities for energy improvements in steel foundry melting operations resulting from this research has the potential of making a major impact on the overall energy consumption and costs for steel foundries.

Most of the electrical energy in an induction or arc furnace operation is consumed in melting the steel scrap charge. However, significant amounts of electrical melting energy are consumed and lost to inefficiencies in the electrical system and melting equipment, water cooling system, conduction through walls and radiation losses, poor scrap selection and blending, furnace delays, high tap temperatures, sensible heat in the slag, off-gas and dust, metallic yield and in superheating the steel to high temperatures to make up for low efficiencies. The initial stage of the research at the Missouri University of Science and Technology (Missouri S\&T) was to complete a comprehensive benchmarking study of the variability in melting practices used by the steel foundry industry and evaluate the effects of this variability on energy consumption. The purpose of this study was to determine practices that were successful in reducing energy consumption and develop new melting practices/technologies to improve the energy efficiency of melting in steel foundry operations. The remaining stages of the project included laboratory studies at Missouri S\&T combined with industrial plant trials at cooperating steel foundries to demonstrate energy reductions techniques in steel foundries.

\subsection{Specific Goals and Objectives}

Goals and objectives were divided into a six specific tasks as follows:

TASK 1 - Research wrought industry energy usage. Energy usage during melting operations in the wrought steel industry was researched through a combination of literature search, industrial surveys, and data gathering in plant visits. The primary purpose of this task was to provide supporting data and technical information to the steel foundry industry which will help steel foundries recognize areas of opportunity for energy savings through technical improvements.

TASK 2 - Research steel casting industry energy usage. Concurrent with Task 1, the team researched the current state of energy usage during melting operations in the steel foundry industry. This benchmarking study was done through literature review, comprehensive surveys of energy use by steel foundry melting operations, and visits to each of the participating 
foundries. Energy consumption data collected included electrical energy consumed during induction or arc furnace melting based on factors such as scrap selection and blending, inefficiencies in the electrical system and melting equipment, water cooling systems, conduction through walls and radiation losses, furnace delays, tap temperatures, sensible heat losses (slag, off-gas and dust), metallic yield and areas of yield loss, and melting/casting schedule. The results from this study included a comprehensive summary of the variability in melting practices used by the steel foundry industry and the effects this variability has on energy consumption.

TASK 3 - Determine opportunities for technical transfer - wrought to steel casting industry. The results from tasks 1 and 2 were evaluated to determine the best practices for energy consumption, areas of opportunity for energy improvement, and laboratory experiments and trials to study and develop new melting practices/technologies to improve the energy efficiency of melting in steel foundry operations. Foundries for extended melting trials were selected.

TASK 4 - Industrial trials. Industrial trials were conducted to determine the effects of making changes in melting practices on energy efficiency. Work was completed in both induction furnaces and electric arc furnaces. Six to eight trials were anticipated in the final two years of the project. Results from the industry trials were used in combination with laboratory studies to develop and validate an energy model calculator for steel foundries.

TASK 5 - Laboratory study of factors affecting energy consumption during melting in foundries. Original plans were to conduct controlled melting studies in the induction furnace at Missouri S\&T to evaluate the effects of different types of ferrous scrap and melting practices on energy consumption for steel foundries. Based on the findings in Task 1 and 2, the focus of this work was made on developing better ladles to reduce energy losses during holding between the furnace and pouring. This work supplemented the industrial trials and was used with the industrial trials to develop the energy model of steel foundry melting operations.

TASK 6 - Energy model of steel foundry melting operations. A computer spreadsheet based calculator model was developed to evaluate the effect of melting parameters on energy usage and efficiency in steel foundry melting operations. The model was developed using results from research studies in both the laboratory and industrial trials, and thermodynamic data. The model was validated using data from industrial trials.

\subsection{Team Members}

Dr. Kent Peaslee was the principal investigator and project manager, coordinating the efforts in research of the wrought industry energy usage, foundry energy usage and determining the opportunities for technical transfer between the wrought industry and steel casting industry. In addition, he directed the efforts in developing the energy model for steel foundry operations and directed the industrial trials. He is the F. Kenneth Iverson Chair of Steelmaking Technology and Curators Professor of Metallurgical Engineering at Missouri S\&T. He has 13 years of operating and engineering experience in the steel melting and casting industry and over 20 years at Missouri S\&T doing steel melting and casting research and teaching. His industrial experience, expertise and research has focused on ferrous scrap characterization, EAF and BOF melting, modeling and optimization of melting operations, ladle metallurgy, steel-refractory interactions and environmental aspects of steel manufacturing.

Dr. Von Richards directed efforts in research of the steel casting industry energy usage and the laboratory foundry experiments. Dr. Richards' is the Robert V. Wolf Casting Professor at 
Missouri S\&T and has 20 years metal casting teaching experience and 13 years in applied research and engineering in the casting industry. His research has included DOE funded projects on ferrous scrap melting, cupola charging, cast iron metallurgy, and investment casting for the foundry industry.

Dr. Jeffrey Smith assisted with the industrial trials and concentrated on refractory selection and design for energy reduction in melting furnaces and ladles. Dr. Smith is an Associate Professor of Ceramic Engineering at Missouri S\&T with over 20 years of refractory research experience and has directed two DOE funded research programs related to refractory development for both the wrought and foundry steel industries.

Dr. Simon Lekakh is a Research Professor in Metallurgical Engineering at Missouri S\&T with 35 years of steel casting research. He assisted with the day to day laboratory experiments at Missouri S\&T and with the industrial trials. 


\section{Results and Discussion}

A summary of the research highlights is included in this final report by research task. The full publications (see list in section 6.1) include more details from the research.

\subsection{TASKS 1 -Research wrought industry energy usage and TASK 2 Research steel casting industry energy usage}

\subsection{1 - Alloy recovery and control in steel foundry melting}

\subsection{2 - Benchmarking of Steel Foundry Industry}

One of the highest areas of cost in a melting operation is alloy additions. Therefore, if a foundry can have a better understanding of the factors that determine alloy recovery and improve control of the final chemistry, significant costs and energy can be saved while producing more consistent quality steel castings. Alloy control implies that a foundry has the ability to meet the chemistry requirements for a given grade consistently. As illustrated in Figure 1, the typical foundry practice is to aim above the minimum alloy requirement, usually at or just slightly above the mid-specification range, avoiding off-specification castings. As control is improved, alloy savings can be realized by targeting a much tighter internal chemistry specification at the lower end of the alloy requirement (see Figure 1). Both alloy recovery and melt practice play key roles in foundries being able to utilize alloy control.

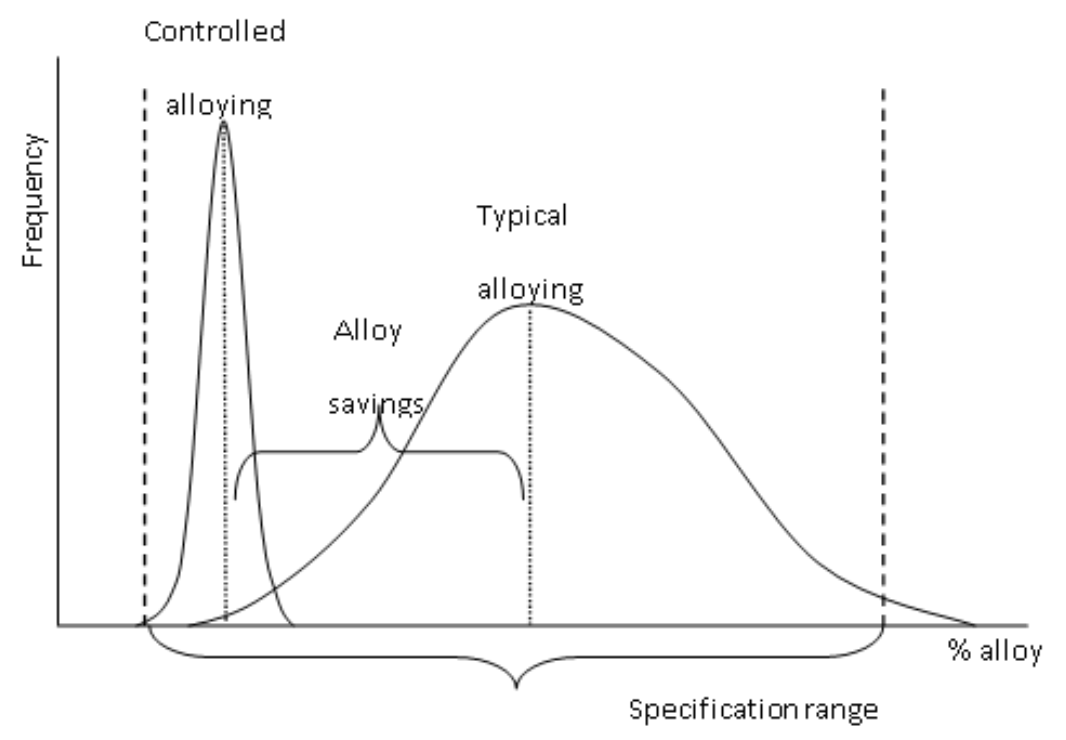

Figure 1 Reduction in alloy use through controlled alloying in steel foundries

Alloy recovery in industrial operations is affected by many factors. Oxidation of the alloy is usually the primary cause of poor or erratic recovery. Research suggests that ferroalloy recovery is a function of the dissolution rate of the alloy, density of the alloy, and dissolved oxygen in the liquid steel (for nitride-forming alloys, dissolved nitrogen must also be included). ${ }^{2}$ It was found that increasing the dissolved oxygen in the steel lowered the alloy recovery and decreased the dissolution rate of alloys with melting points greater than steel. The reduction in dissolution rate was attributed to the possible formation of a refractory oxide on the alloy surface. Important sources of oxygen are furnace slag and air contact (slag carryover and air entrainment during tapping). ${ }^{3}$ Other sources of oxygen include slag remaining in the furnace (or ladle) from previous 
heats, oxygen dissolved in the metal, air carried into the melt by alloy additions, and from refractory-metal interactions.

Wrought steel producers typically do not add alloys to the melting furnace and make all of the additions to the ladle either during tap or in a ladle metallurgy station/ladle furnace ${ }^{4,5}$. By, moving chemical correction from the melting furnace to the ladle, the modern steel mini-mill practice of minimizing time and energy consumption in the EAF has been achieved. Of course, the effectiveness of the above described alloying methods depends on ladle volume. Thus, not all of these techniques can be effectively used in foundries which operate with multiple smaller ladles. The main aim of this research subtask was to evaluate the recovery of alloying additives in foundry practices and investigate the benefits of controlled alloying.

Plant trials were conducted at seven steel foundries equipped with induction furnaces (IF) and electric arc furnaces (EAF). Steel capacity in the IF's ranged from 900 to 9,500 lbs. EAF capacity ranged from 6,500 to 20,000 lbs. Melting observations and statistical data were collected to analyze alloying additive recovery and steel chemistry distribution in typical casting practices. Three to five trial heats were melted and observed in each foundry collecting information on the melting procedure including power practices, weight and composition of charge materials, weight and composition of additives, alloying procedure and steel chemistries. All of the foundries weighed charge materials and tested the chemistry analysis before and after the alloy additions. However, some foundries weighed additives more precisely than others. At each foundry, an additional 20 to 155 heats were studied by recording the charge weight and compositions, preliminary and final steel chemistry, and the weight of additives from statistical data available at the plant (charge sheets, heat logs, cast logs, computer databases, etc.).

This study showed that there is a vast variety of factors which influence the recovery of ferroalloys and the ability to tightly control final chemical composition. Table 1 shows the wide variation in $M n$ recoveries and alloy control capabilities between six of the industrial foundries studied, the laboratory induction furnace at Missouri S\&T, and plant trials at a ladle metallurgy furnace (LMF) in a wrought steel facility. The best industrial foundry results were achieved in Foundry B, where recoveries of $\mathrm{Mn}, \mathrm{Cr}, \mathrm{Ni}$, and $\mathrm{Mo}$ were high and chemistry control was tighter. The laboratory results at Missouri S\&T were slightly better than the foundry industrial operations due to the improved recovery in the ladle. Some of the factors observed in this study that affected alloy recovery and control (negative and positive) in induction furnaces included: oxidizing conditions (melting in air, additives with charge, and slag on surface during alloying), induction stirring after alloy addition, time of addition (charge, in furnace, or in ladle), and accuracy of weights and additions.

Alloying in EAF furnaces was generally less accurate than in induction furnaces resulting in chemistry distributions with more scatter (see Figure 2). It was demonstrated that significant improvements in the alloy recovery and control are possible in foundries when alloys are added in the ladle. Some of the factors observed in this study that affected alloy recovery and control (negative and positive) in EAFs included: Lack of intense stirring resulting in less homogeneous chemistry, presence of slag, time of addition (with charge-low recovery, in furnace, or in ladlehigh recovery), accuracy of weights and additions, and dipping electrodes expensive method of adding carbon.

In summary, steel foundries typically are not controlling alloy additions to the tight levels (see Figure 2) that would reduce costs and energy. This study showed that there are many 
opportunities for improvements that will save alloying costs and energy savings as well as providing customers with steel castings that are more consistent in properties.

Table 1 Recovery and variation of $M n$ in different foundries and wrought industry (LMF)

\begin{tabular}{|c|c|c|c|c|c|c|c|c|}
\hline \multirow{2}{*}{$\%$} & \multicolumn{3}{|c|}{ IF } & \multicolumn{5}{|c|}{ EAF } \\
\cline { 2 - 9 } & $\mathrm{A}$ & $\mathrm{B}$ & $\mathrm{S} \& \mathrm{~T}$ & $\mathrm{C}$ & $\mathrm{E}$ & $\mathrm{D}$ & $\mathrm{G}$ & LMF \\
\hline Recovery & 65 & 78 & 92 & - & $69-80$ & 83 & - & 95 \\
\hline SD & 0.093 & 0.037 & 0.023 & 0.116 & $0.06-0.17$ & 0.091 & 0.107 & .052 \\
\hline SD/M & 0.127 & 0.037 & 0.035 & 0.160 & $0.069-0.198$ & 0.121 & 0.181 & 0.043 \\
\hline SR/SD & 2.1 & 8.1 & NA & 4.3 & $2.3-7.1$ & 3.2 & 3.7 & 9.3 \\
\hline
\end{tabular}

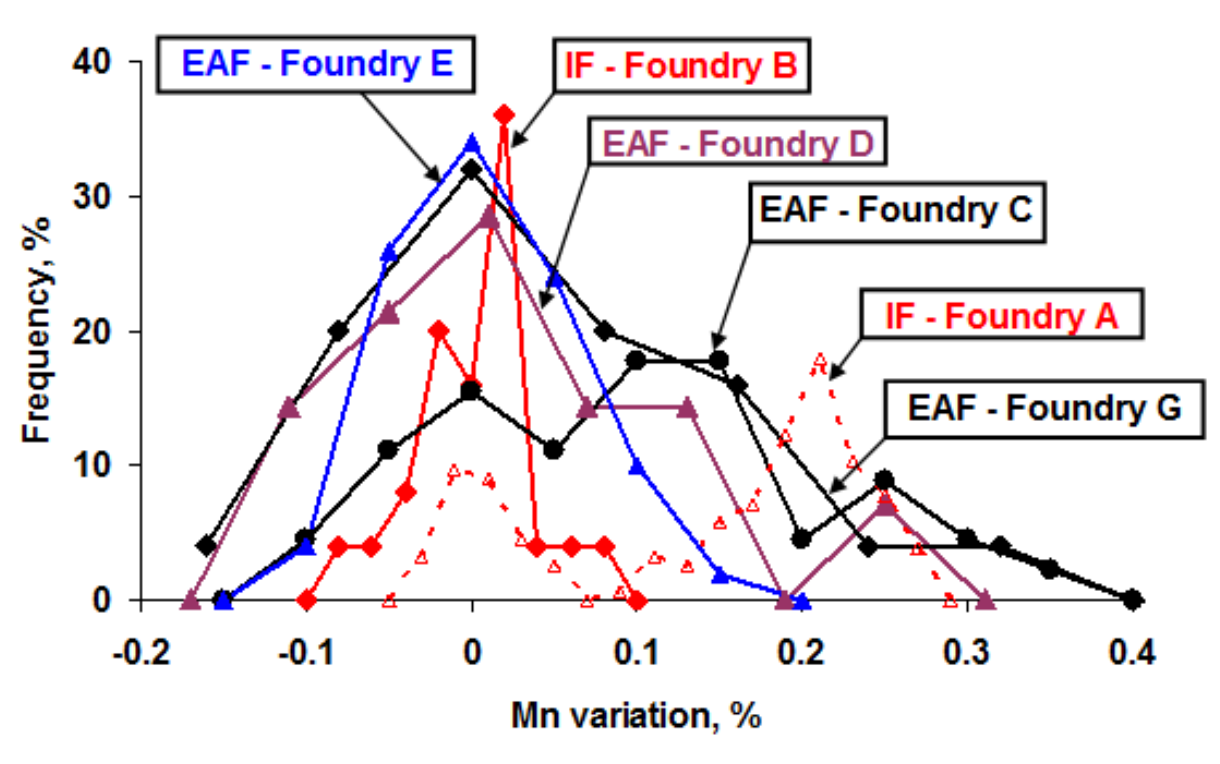

Figure 2 Variation of manganese concentration in steel melted in different foundries

\subsection{2 - Benchmarking of Steel Foundry Industry}

The purpose of this aspect of the research is to provide benchmark information on the energy consumption for steel melting in the steel foundry industry based on the type of charge materials, melting technologies, furnace type, and operating practices. Experimental measurements, statistical data, heat transfer calculations, and numerical simulations were used to evaluate the energy consumption and heat losses during steel melting in seven different steel foundries utilizing both IF and EAF melting. Three to five trial heats were melted in which detailed energy data was generated and collected including power settings and power on times, electrical consumption, weights and compositions of all charge materials, weights of liquid metal and amount cast into product and pigged, oxygen and natural gas consumption and frequent temperature measurements using immersion thermocouples and high temperature infrared camera. In addition to the detailed data collected during the melting trials, information was collected from 20 to 100 additional heats at each foundry using production reports to provide sufficient data on each foundry for statistical analysis of the melting time, energy consumption, charge materials, and steel chemistry.

One important part of this study was an evaluation of the total energy use during the melting operation in each foundry. To evaluate the total energy consumption, an energy balance during 
melting was required which included determining the typical energy losses to refractories, water cooling, electrical systems, and radiation. "Power-off" experiments were completed both free of slag and under slag allowing evaluation of total and radiation heat losses and isothermal holding experiments provided data on the minimum amount of electrical energy required to compensate for electrical and heat losses. Two IF foundries were equipped with thermocouples and flow meters for each of the cooling water lines. This allowed for measurements of the conduction heat losses through the refractory as well as the electrically generated heat (Joule) losses when combining the water flow and temperature measurements with the normal, power-off, and isothermal holding experiments. These experiments provided validation for the thermal modeling required to estimate the losses at facilities not having full instrumentation. In these cases, only cumulative and operational electrical energy efficiency were measured and calculated.

Figure 3a reflects the spectrum of energy consumption for steel melting in induction furnaces at four foundries. The electrical energy varied from a low of $450 \mathrm{kWh} /$ ton to a high of $800 \mathrm{kWh} / \mathrm{ton}$ representing $35 \%$ to $235 \%$ excess energy from the approximately $350 \mathrm{kWh} / \mathrm{ton}$ required to melt room temperature scrap and heat to tap temperature. There were several factors that helped contribute to decreasing the energy consumption in IF's including melting in a furnace with a hot lining, shorter melting times achieved by higher density charges, continuous charging of scrap during melt, and larger power supplies (KW capacity per ton). Melting under slag (coagulant) decreased radiation losses (high temperature liquid metal not exposed to atmosphere) and furnace lids constructed from low thermal conductivity ceramics decreased heat losses (conduction and radiation).

Figure $3 b$ compares the electrical energy consumption at five EAF steel foundry furnaces participating in this study. Heat time in these furnaces ranged from a low of 40 minutes (Furnaces \#1 and \#2 at Foundry E) to a high of 240 minutes (Foundry G). The electrical energy consumption ranged from a low of $320 \mathrm{kWh} /$ ton (Furnace \#2 at Foundry E) to a high of 780 $\mathrm{kWh} /$ ton (Foundry G). The two EAFs with the lowest electrical consumption both employed chemical energy (oxy-fuel burners) which significantly decreased the required electrical energy and the heat time. When considering total energy (chemical plus electrical), furnaces utilizing oxy-fuel burners were more efficient (79\%) than those without oxy-fuel burners (69\%). In general, accurate energy data was difficult to obtain because most foundries did not have complete instrumentation or measuring devices to monitor energy consumption. 


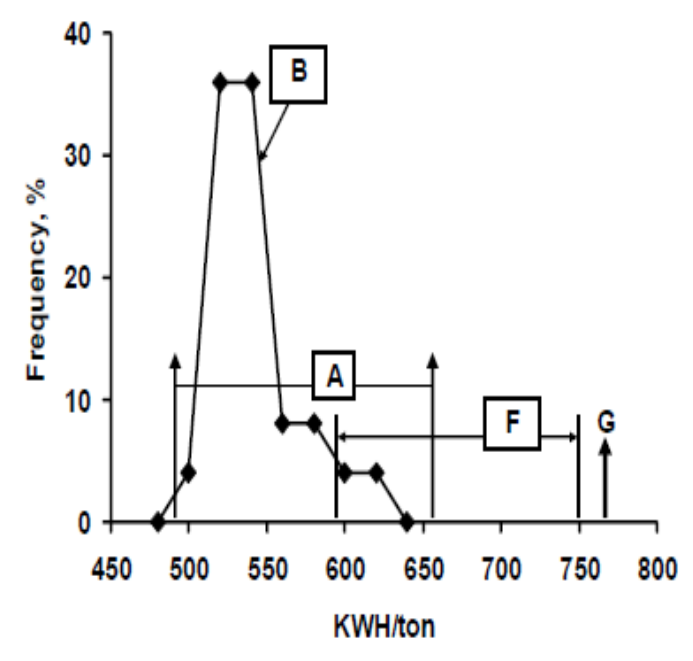

a) Electrical Energy in IFs

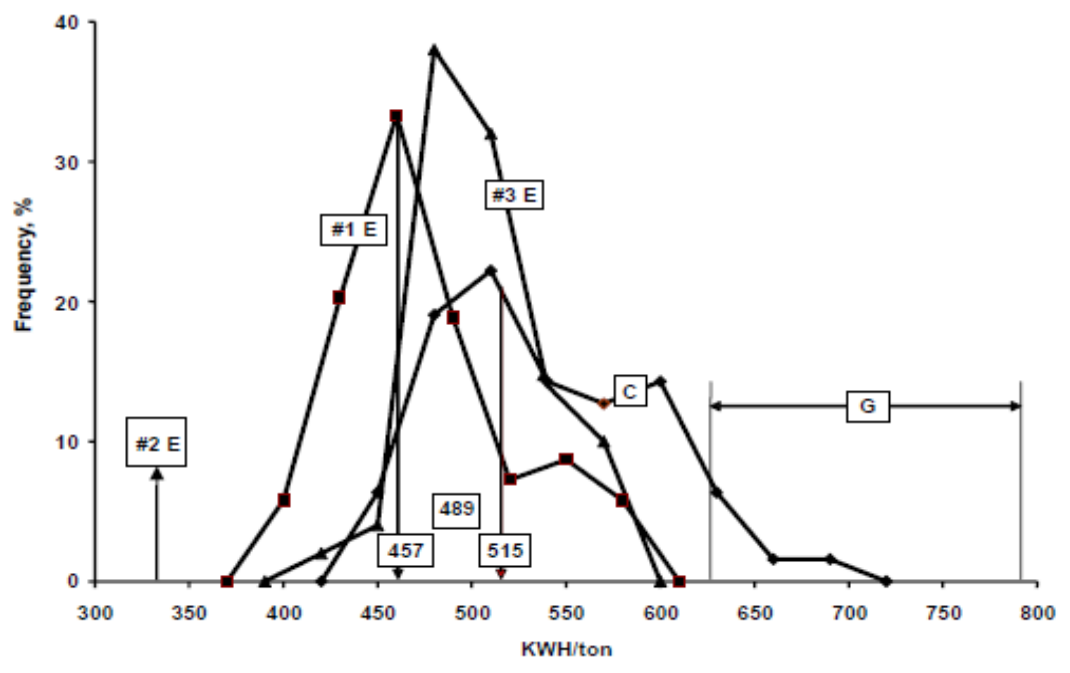

b) Electrical Energy in EAFs

Figure 3 Electrical energy consumption comparison for steel foundries

\subsection{TASK 3 - Determine opportunities for technical transfer - wrought to steel casting}

Analyzing the findings from the study of melting practices and energy consumption in the wrought industry (Task 1) and the study of melting practices and energy consumption in the foundry industry (Task 2) revealed several opportunities for technical transfer and melting improvements that could improve the energy consumption, productivity, and cost in steel foundry melting operations. The steel mini-mill industry has utilized technologies such as computerized scheduling to reduce delays and energy/production losses, foamy slag, heavy use of chemical energy (oxy-fuel burners, oxygen during melt-down, post-combustion), better refractories, energy instrumentation and real time computer monitoring and controls. Table 2 compares the energy consumption in EAFs from foundries with data collected at several minimills in the US.

Table 2 Comparison of energy (min-ave- max) for EAFs in foundries and mini-mills

\begin{tabular}{|l|c|c|}
\hline & Data from 6 Foundry EAFs & Data from 8 mini-mill EAFs \\
\hline Electrical Energy $(\mathrm{kWh} / \mathrm{t})$ & $330-\mathbf{5 0 0}-780$ & $320-\mathbf{3 7 7}-424$ \\
\hline Chemical Energy $(\mathrm{kWh} / \mathrm{t})$ & $30-\mathbf{6 0}-120$ & $149-\mathbf{1 8 3}-244$ \\
\hline Total Energy $(\mathrm{chem}+\mathrm{elec})$ & $440-\mathbf{5 6 0}-820$ & $535-\mathbf{5 6 0}-603$ \\
\hline Average Heat time $($ minutes) & $54-\mathbf{9 0}-120$ & $40-\mathbf{5 4}-73$ \\
\hline Power-on-time $(\%)$ & $30-\mathbf{6 0}-75$ & $76-\mathbf{8 4}-91$ \\
\hline
\end{tabular}

Some of the important findings from the initial benchmarking study (Tasks 1 and 2) led to areas of research and industrial trials pursued in the research project. These areas are summarized below:

- $\quad$ Starting up cold furnaces increased the energy required by as much as $30-50 \%$ on the first heat. Foundries were encouraged to change scheduling (fewer melting days per week, fewer furnaces, etc.) to maximize the number of heats each day in a single furnace.

- $\quad$ Productivity delays resulted in higher energy losses through conduction to the refractory and from liquid surface radiation. Foundries were encouraged to institute programs 
aimed at reducing down-time during melting to avoid these delays and the resulting energy losses. These included preventive maintenance, better scheduling to avoid waiting on scrap charges or molds, etc.

- Most foundries lacked furnace instrumentation (real-time electrical monitoring, electrical regulation, PLCs, computer controls, etc.). Foundries were encouraged to add instrumentation to help monitor and reduce total energy consumption.

- Chemical energy is one of the most effective methods of reducing electrical consumption and increasing productivity in the wrought industry through the use of oxy-fuel burners, increased oxygen throughout the heat with supersonic oxygen lances and foamy slag practices. Most foundries did not use chemical energy in the benchmarking study although the most efficient foundries (highest productivity, lowest $\mathrm{kWh} /$ ton - practices similar to wrought) used significant amounts of energy through oxy-fuel burners and oxygen use during melting. Research in Task 4 was aimed at demonstrating the advantages of chemical energy use in foundries.

- Ladle practices were found to be an area that wasted energy in the foundry industry with insufficiently preheated ladles, lack of covers during holding and high thermal conductivity linings. These inefficiencies cause foundries to use more energy in heating the steel in the furnace to higher tap temperatures, increasing total energy consumption. Research in Task 5 was directed at improving ladle refractories and ladle practice to reduce the losses and increase energy efficiency during melting.

- Scheduling was found to be one of the most important and high impact methods of improving energy efficiency with no capital investment. Plants that are driven by productivity (tap as many heats as possible every shift) are far more energy efficient than plants that are limited in productivity by the schedule (limited number of heats per shift). Research in Task 4 was directed at showing improvements in energy efficiency due to improved scheduling.

\subsection{TASK 4 - Industrial trials.}

\subsection{1 - Induction Furnace Studies - Improved Scheduling}

Based on the research in Tasks 1 through 3, industrial trials were conducted at individual foundries with the goal of saving energy through improved production controls and process management techniques that provide for more consistent melting. In addition, these trials used melting technological improvements not requiring capital investments but capable of saving significant energy and materials. This research focuses on the results from a foundry that made technological improvements based on the findings in the earlier benchmarking study.

One industrial trial was conducted at a foundry that melts low, medium carbon and stainless steel in medium frequency induction $500 \mathrm{KW}$ furnaces of 2,000 lbs. capacity. During the earlier benchmarking research in 2004, energy consumption averaged 500 and $666 \mathrm{kWh} /$ ton for melting on hot and cold linings, respectively. The main heat losses during steel melting were attributed to heat accumulation by the cold lining as well as radiation and conduction of heat during the 30-45 minute final chemistry correction period (see Figure $4 \mathrm{a}$ and 5a). Operational energy efficiency was found to reach a maximum of 70 to $80 \%$ while melting solid charge materials but decreased dramatically to nearly zero (just enough energy to maintain temperature) during the final chemistry correction period. The energy efficiency was between 30 and 50\% during heating of 
the molten bath to the tap temperature under an open surface (Figure 6). Statistical analysis indicated a wide variation in the total energy consumption with the lowest observed values of the total energy consumption per ton being near to the best practices observed in other foundries equipped with induction furnaces. However, the wide variation in energy efficiency between heats resulted in an average electrical energy consumption that was higher than the average of other induction foundries utilizing best practices. In addition to the electrical energy consumed, an additional 300,000 - 400,000 BTU of natural gas was used during the 1.5-2.5 hours of ladle preheat for each heat. Total temperature losses measured during tapping and pouring ranged from $110^{\circ} \mathrm{F}$ to $150^{\circ} \mathrm{F}$.

Recommendations for energy savings from Missouri S\&T's 2004 industrial trials and benchmarking study were implemented by the industrial foundry in an attempt to increase productivity, reduce energy consumption, save operating costs, and increase quality and safety. These improvements were made without an increased capital investment and included:

- optimize scheduling to minimize the number of heats melted at less than full furnace capacity (reducing scrap and decreasing energy)

- improve production schedule to decrease the number of cold heats on a lining

- gas preheat the induction lining prior to the first heat (minimize thermal shock to the refractories and reduce energy requirements of first heat)

- change alloying practice to minimize alloys added to charge and only add alloys immediately after deslagging the furnace

- rewrite melting practices and train employees to consistently melt the same way (improve consistency in hitting chemistries, decrease final chemistry correction period and reduced tap-to-tap time)

- decrease radiation losses by using covers during melting and pouring

- instituted an effective preventive maintenance program to reduce delays in the furnace

- additional training of employees to adhere to improved melting practices

After implementation of these improvements, the industrial foundry was revisited and a series of industrial trials performed to evaluate the effects of these changes. Electrical energy was reduced by an average of $15 \%$ during the first heat on a furnace due to the improved preheat practices employed (Table 3). Electrical energy was reduced by 5-10\% on heats melted in hot linings. A comparison of the energy requirements is illustrated in Figure 4 (first cold heat) and Figure 5 (hot lining). Figure 6 illustrates the improvements observed in energy efficiency due to the changes made during the different melting periods of heats on hot and cold linings. The effects of optimizing the scheduling decreased tap to tap times and the percentage of first heats to $11.6 \%$.

The new practice of gas preheating the IF lining before the first heat increased the average temperature of the lining to $1550^{\circ} \mathrm{F}$ before melting significantly decreased the lining accumulation heat losses (nearly $100 \mathrm{kWh} /$ ton reduction). In addition, this practice helps minimize the thermal shock to the refractories improving refractory wear. This improvement coupled with reducing the percentage of heats melted on a cold lining and other melting improvements resulted in a $20 \%$ reduction in refractory usage with the new practices. Covering 
the bath during melting and the ladle during pouring decreased the radiation heat losses and stabilized pouring temperatures.

Table 3 Comparison of heats before and after process changes

\begin{tabular}{|c|c|c|c|c|c|c|}
\hline $\begin{array}{c}\text { Before } \\
\text { or after } \\
\text { changes }\end{array}$ & Steel & Lining & Charge & $\begin{array}{c}\text { Corrections, } \\
\#\end{array}$ & $\begin{array}{c}\text { Melting } \\
\text { Time, min }\end{array}$ & $\mathrm{kWh} / \mathrm{t}$ \\
\hline Before & WCB & Cold & Solid & 1 & 207 & 653 \\
\hline Before & WCB & Hot & Solid +200 heel & 1 & 120 & 545 \\
\hline After & WCB & Hot & Solid & 1 & 114 & 519 \\
\hline After & WCB & Hot & Solid +200 heel & 1 & 104 & 517 \\
\hline After & CF8M & Preheated & Solid & 2 & 130 & 562 \\
\hline After & CF8M & Hot & Solid $+350 h e e l$ & 2 & 106 & 534 \\
\hline
\end{tabular}

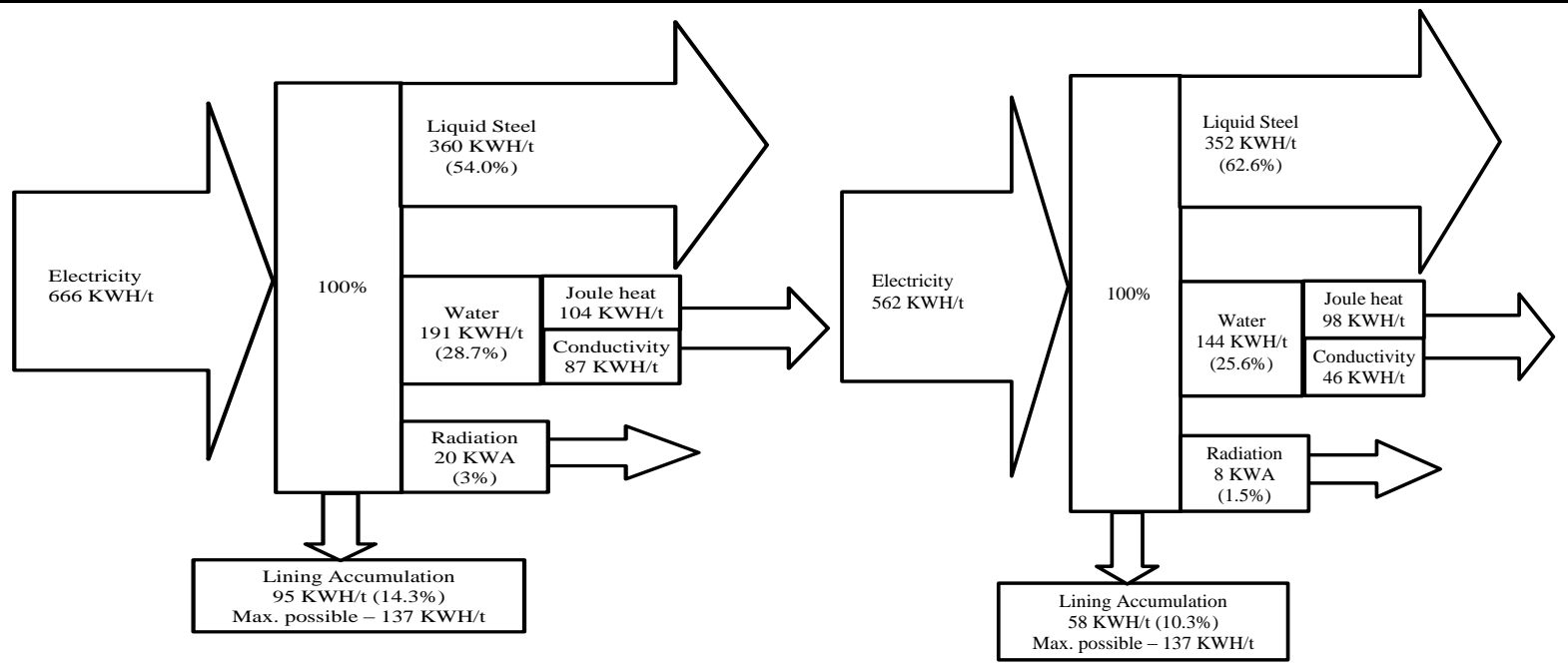
a) "cold" practice before changes
b) "gas preheated" practice after changes

Figure 4 Modified Sankey-diagrams (energy flow) for first heats on a lining

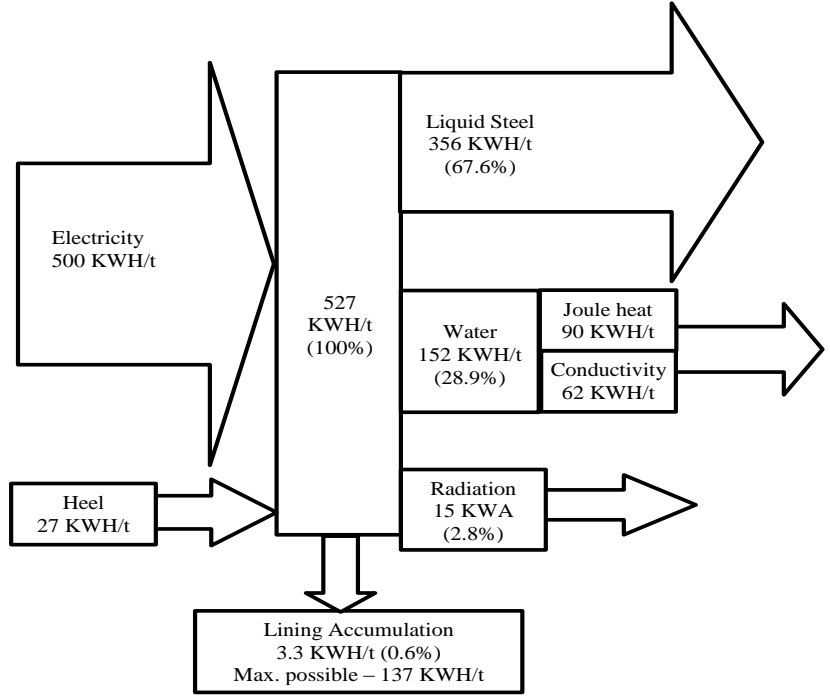

a) Before change(open)

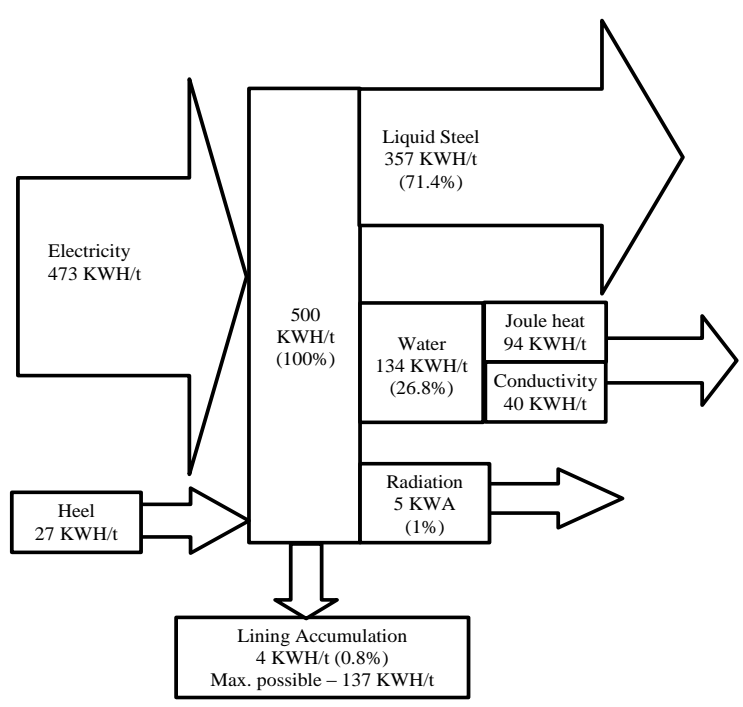

b) After changes (with covers)

Figure 5 Modified Sankey-diagrams (energy flow) of heats in hot lining with $200 \mathrm{lb}$ heel 


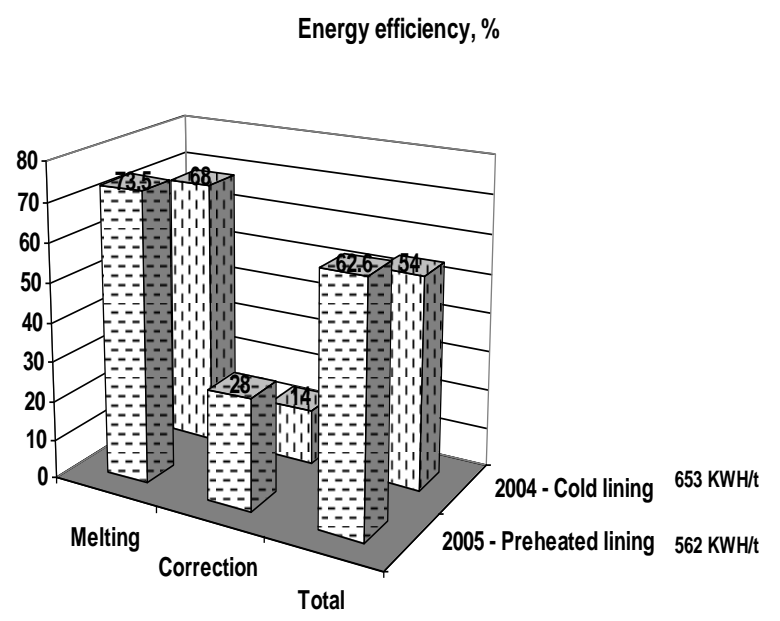

a) first heat of the day

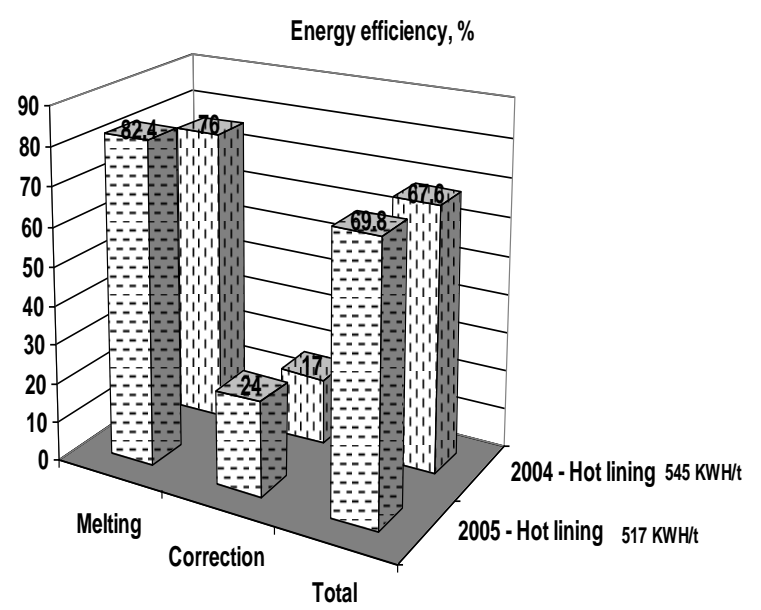

b) heats on a hot lining

Figure 6 Melting energy efficiency before (2004) and after (2005) process improvements

\subsection{2 - Induction Furnace Trials - Alloy Control}

This industrial trial was completed in a steel foundry using an induction furnace of 2,000 lbs. capacity. In the 2004 benchmarking study of 155 heats at this foundry, alloy recovery variation was found to be lower for ferroalloys added to the charge because of the greater potential for oxidation during the melting process. Also, recoveries of $M n$ and $S i$ added to the melt were inconsistent with some heat having high recoveries and others much lower than expected. In observing alloying, variations were found to be caused in some cases by ferroalloy additions into a melt surface covered by slag. The distribution of the final chemistries by alloying element characterizes the consistency of melting practices. The ratio of the standard deviation (SD) for elements in the final chemistry to the specification range (SR) demonstrate the capability of staying within the specification and also whether or not the element aim range can be reduced to save alloying costs. From a statistical basis, a SR/SD ratio of 4.0 or more indicates that $95.5 \%$ of the heats would be within the specification range based on a normal data distribution. In addition, developing practices that improve alloy recovery both in $\%$ and in consistency allows the foundry to reduce the aim (illustrated in Figure 1) reducing alloying cost and energy required for melting (and manufacturing) alloys. Mn was used for this study. As shown in Table 4, the SR/SD ratio during the benchmarking study in 2004 was 2.1 indicating that alloying practices needed to be changed to result in more consistent practices and to save alloying costs. In 2005, melting practices were rewritten to implement changes recommended by this project and operators retrained to minimize alloys added to the charge, sample melts more consistently and avoid adding alloys through slag. Table 4 and Figure 7 illustrate improvements in Mn recovery and improved consistency achieved through the new melting practices. The change represents a $20 \%$ decrease in the $\mathrm{Mn}$ alloys added to make the same grade as before the changes.

Table 4 Comparison of final $M n$ before (2004) and after (2005) process changes

\begin{tabular}{|l|c|c|}
\hline & 2004 & 2005 \\
\hline Average final Mn & 0.69 & 0.57 \\
\hline Mn Standard deviation (SD) & 0.097 & 0.031 \\
\hline Mn Specification Range (SR) & $0.4-0.6$ & $0.4-0.6$ \\
\hline Mn SR/SD & $\mathbf{2 . 1}$ & $\mathbf{6 . 4}$ \\
\hline
\end{tabular}




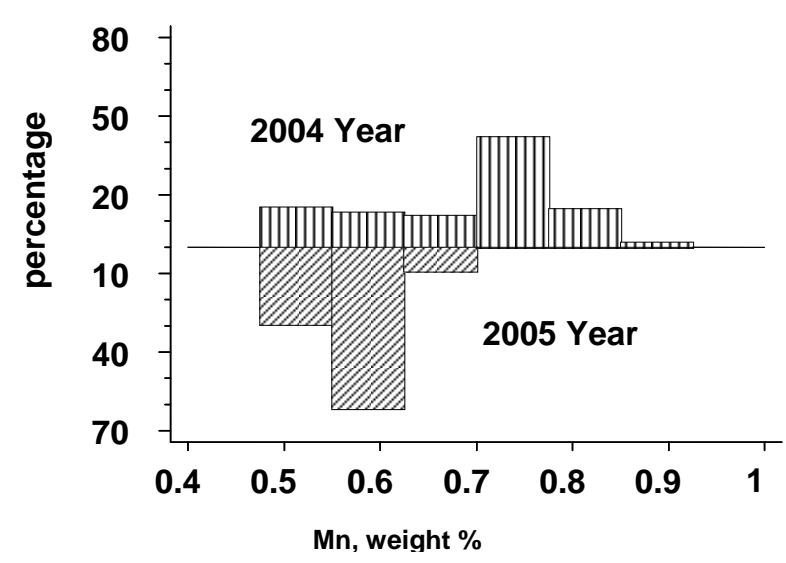

a) Average $\mathrm{Mn}$ in heats studied

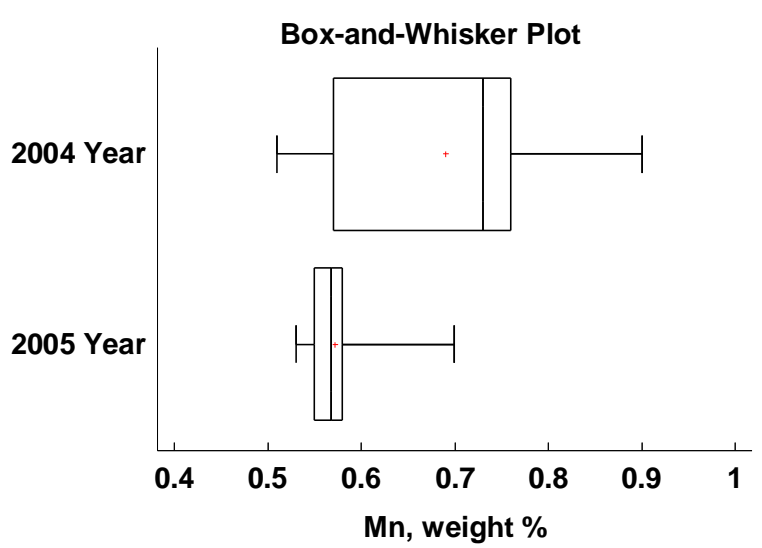

b) Box-and-Whisker Plot of Mn variation

Figure 7 Mn variation in WCB product before (2004) and after (2005) practice changes

\subsection{3 - Electric Furnace Trials - Chemical Energy - SiC}

Supplemental chemical energy is a promising way for decreasing electrical energy consumption and increasing the efficiency and productivity of melting steel in foundry EAFs. There are many technologies that are possible for introducing supplemental chemical energy into the EAF steel melting process including preheating the scrap, oxy-fuel burners for heating cold regions of the solid charge during melt down, post-combustion of $\mathrm{CO}$ produced in the furnace to $\mathrm{CO}_{2}$, and exothermic heat from oxidation reactions within the melt.

This series of industrial trials studied the use of exothermic heat from oxidation reactions within the melt to increase energy efficiency during the flat bath period. Opportunities to increase the energy efficiency are greatest during this period because the electrical energy efficiency drops significantly when heating liquid steel with an open arc in air. A significant portion of the arc energy is reflected from the arc and bath surface to the sidewalls and roof where the energy is lost in heating (and often melting) refractory rather than steel. Although scrap preheating systems, oxy-fuel burners and post-combustion of $C O$ are effective methods of adding chemical energy, they all require additional capital investment, but the addition of a material such as $\mathrm{SiC}$ which produces exothermic reactions during the oxygen blow does not require any capital investment. Figure 8 illustrates the advantage of using $\mathrm{SiC}$ as a source of chemical energy. Because the heat is generated within the liquid steel, heat transfer efficiency from the exothermic reactions should be nearly $100 \%$, much higher than the typical $40 \%$ efficiency for postcombustion of $C O$ above the bath.

In this research work, the amount of exothermic heat generated during oxygen boiling was increased by adding $\mathrm{SiC}$ with the solid charge. The purpose of this investigation was to evaluate the energy and operational effects of adding enough $\mathrm{SiC}$ with the scrap charge to represent 0.4$0.6 \%$ of the charge weight in two foundries. The first foundry, Foundry A, uses 20 ton EAFs with no oxy-fuel burner, and the second foundry, Foundry B, uses 5 ton EAFs with oxy-fuel burners. This sub-section summarizes thermodynamic calculations, industrial measurements, heat balances and statistics of the industrial data. 


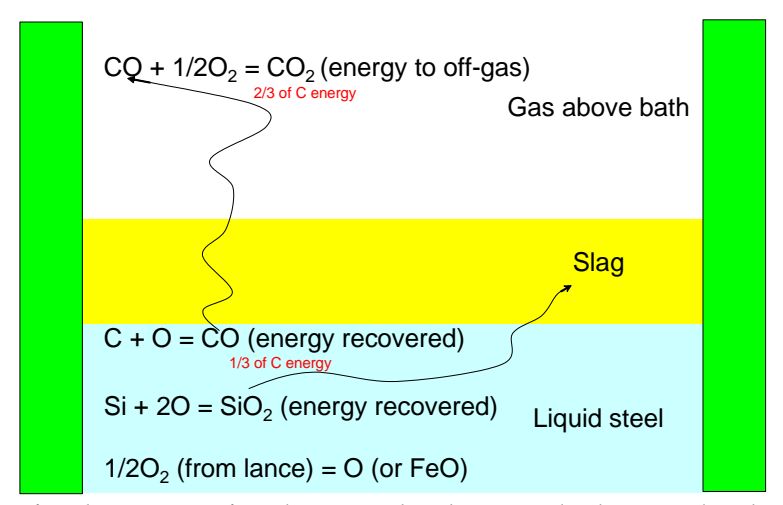

Figure 8 Chemical energy in the steel, slag and above the bath of the EAF

In the first series of industrial trials (Foundry A), $200 \mathrm{lbs}$ of $\mathrm{SiC}(90 \mathrm{w} \% \mathrm{SiC}$ ) were added with the 40,000 lb. scrap charge in the furnace. Carbon additions in the charge, pig iron and/or charge carbon ( 82 weight $\% C$ ), were decreased in these heats to compensate for the additional carbon content in the $\mathrm{SiC}$ (28 weight \% C). Statistical data from 42 trial heats with $\mathrm{SiC}$ were compared to data from a 60 heats without $\mathrm{SiC}$ and summarized in Table 5 and Figure 9. The introduction of $\mathrm{SiC}$ resulted in an average decrease of $37 \mathrm{kWh} / \mathrm{ton}(8 \%)$ in the electrical energy consumption and increased productivity by $6 \%$. The average energy efficiency of the silicon and carbon contained in the $\mathrm{SiC}$ additions was calculated as a ratio of the experimentally measured temperature change to the theoretically possible temperature increase based on the silicon and carbon oxidation during the oxygen blowing. Theoretically, the oxidation of $0.10 \% \mathrm{Si}$ provides $7.77 \mathrm{kWh} / \mathrm{ton}$ of steel. As a result, the addition of $200 \mathrm{lbs}$ of $\mathrm{SiC}$ to a 40,000 $\mathrm{lb}$ charge adds $0.31 \%$ Si to the bath at melt-in. This quantity of $\mathrm{Si}$ would theoretically add $24 \mathrm{kWh} / \mathrm{t}$ of chemical energy. This number is less than the electrical energy saved during experimental measurements ( $37 \mathrm{kWh} / \mathrm{ton})$. The $40 \%$ increase above the theoretical amount experienced was a result of dramatic melting practice improvements in the heats containing $\mathrm{SiC}$. The $\mathrm{SiC}$ addition not only decreased the electrical energy required by replacing electrical energy with chemical energy, but the recovery of the chemical energy from the carbon increased because of the much less violent bath reactions from carbon boiling, reducing the "power-on" time and eliminating delays due to an overactive bath. Early estimates from SiC additions during these trials indicated that the reduced energy cost was greater than the cost of materials for the $\mathrm{SiC}$ addition.

In the second series of industrial trials (Foundry B), $60 \mathrm{lbs}$ of SiC were added to a 5 to 6 ton scrap charge. This furnace was equipped with an oxy-fuel burner and PLC controls. The melting results of 30 heats produced with $\mathrm{SiC}$ were compared with results of 30 heats produced without $\mathrm{SiC}$. A comparison of the two melting practices is summarized in Table 6 and Figure 10.

Table 5 Effect of $\mathrm{SiC}$ additions on energy consumption and productivity (Foundry A)

\begin{tabular}{|l|c|c|c|c|}
\hline \multirow{2}{*}{ Heats } & \multicolumn{2}{|c|}{ Electrical energy consumption } & \multicolumn{2}{c|}{ EAF productivity } \\
\cline { 2 - 5 } & $\mathrm{kWh} /$ ton & Decrease, \% & Ton/hour & Increase, \% \\
\hline Without $\mathrm{SiC}$ & 467.3 & - & 6.22 & - \\
\hline With $\mathrm{SiC}:$ (42 trial heats) & 430.7 & 7.8 & 6.57 & 5.6 \\
\hline
\end{tabular}



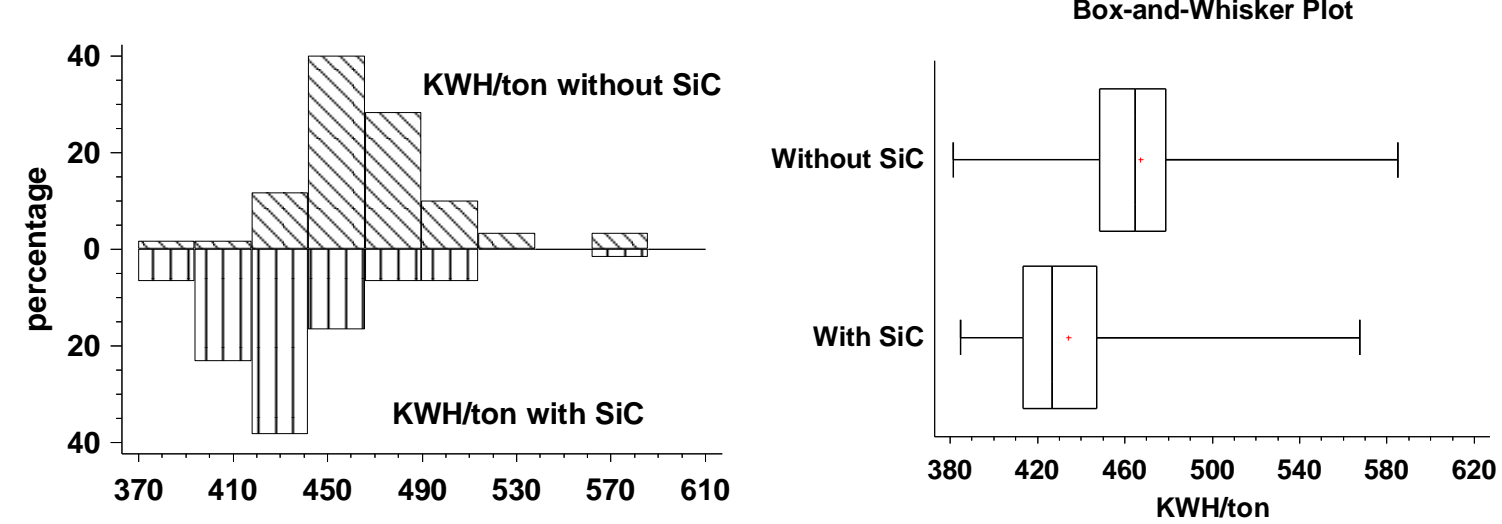

Figure 9 Comparison of electrical energy consumption for melting with $\mathrm{SiC}$ (Foundry A)

Table 6 Effect of $\mathrm{SiC}$ additions on energy consumption and productivity (Foundry B)

\begin{tabular}{|c|c|c|c|c|c|c|}
\hline & \# Heat & $\mathrm{kWh} / \mathrm{t}$ & $\begin{array}{c}\text { EAF } \\
\text { productivity, } \\
\text { t/hour }\end{array}$ & $\begin{array}{c}\text { Melting } \\
\text { productivity, } \\
\text { t/hour }\end{array}$ & $\begin{array}{l}\text { Power-on } \\
\text { time, min }\end{array}$ & $\begin{array}{l}\text { Tap-to-tap } \\
\text { time, min }\end{array}$ \\
\hline $\begin{array}{l}\text { With SiC: } \\
\text {-all heats } \\
\text {-hot lining } \\
\text {-cold lining }\end{array}$ & $\begin{array}{c}33 \\
30 \\
3\end{array}$ & $\begin{array}{l}420.9 \\
410.6 \\
523.3\end{array}$ & 3.04 & 3.63 & 82 & 98 \\
\hline $\begin{array}{l}\text { Base } \\
\text { practice: } \\
\text {-all heats } \\
\text {-hot lining } \\
\text {-cold lining }\end{array}$ & $\begin{array}{c}33 \\
30 \\
3\end{array}$ & $\begin{array}{l}440.6 \\
432.3 \\
524.1\end{array}$ & 2.97 & 3.63 & 80 & 99 \\
\hline
\end{tabular}

Box-and-Whisker Plot
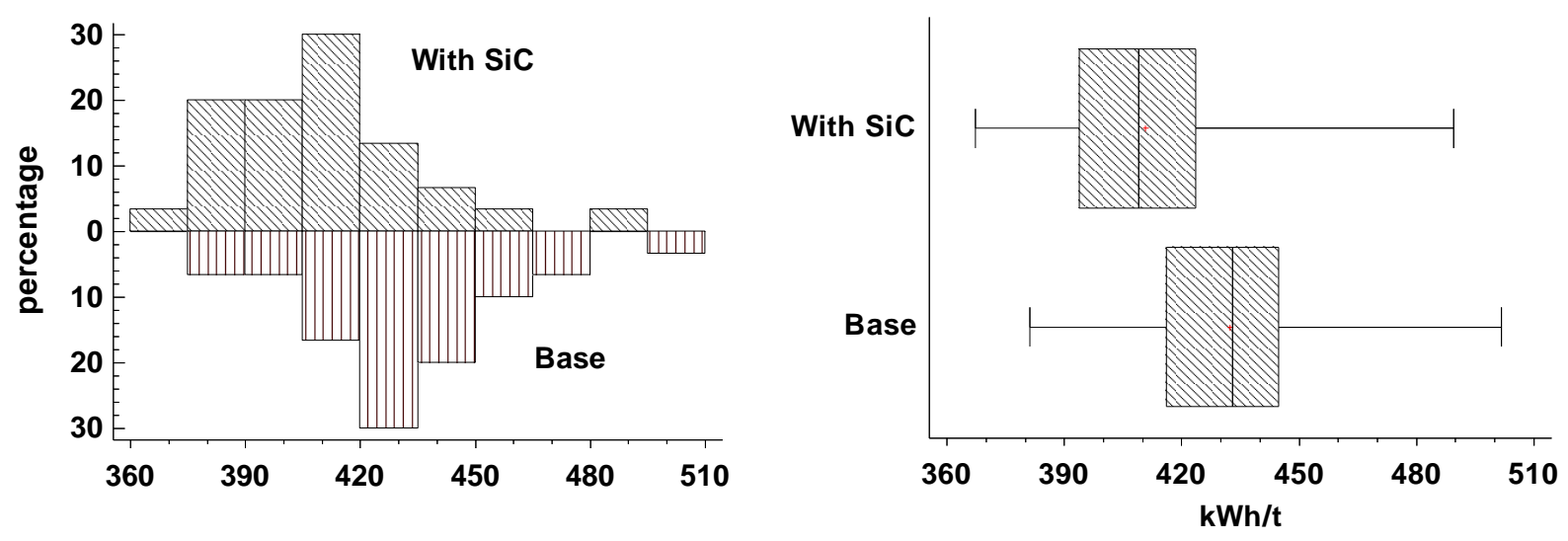

Figure 10 Comparison of electrical energy consumption for melting with $\mathrm{SiC}$ (Foundry B)

In summary, both of the industrial trials showed a noticeable decrease in electrical consumption with the addition of chemical energy provided by $\mathrm{SiC}$. The electrical energy decrease was $8 \%$ when $\mathrm{SiC}$ was the primary agent of chemical energy. Productivity also increased by $6 \%$. In the trials in which there were multiple chemical energy sources ( $\mathrm{SiC}$ plus oxy-fuel burners) the energy decrease due to the $\mathrm{SiC}$ was less $(\sim 5 \%)$ and the productivity increase was insignificant. 
Other melting improvements were a direct result of the $\mathrm{SiC}$ addition including a lowering of the start temperature for oxygen boiling, decrease in the lining erosion, increase in the lifetime of refractory roofs, and safer (less violent) oxygen boiling.

\subsection{4 - Electric Furnace Trials - Chemical Energy - Oxy-Fuel and Co-Jet Trials}

Supplemental chemical energy is a promising method for decreasing electrical energy consumption and increasing the efficiency and productivity of melting steel in foundry electric arc furnaces (EAFs). Both preheating the charge and oxy-fuel burners have the potential of increasing the melting efficiency of the solid scrap charge as illustrated in Figure 11a. During the scrap melting period, electrical energy is input at a fixed rate determined by the electrical transformer settings. Heat losses occur through the furnace sidewalls and roof with some additional losses through sensible heat in the off gas. The addition of chemical energy through the introduction of an oxy-fuel burner or multiple oxy-fuel burners can significantly decrease melting time by eliminating "cold" spots such as the area near the charge door which melt slower than the rest of bath. The reduction in melting time results in a reduction in electrical energy. The overall energy efficiency improves because the reduction in melt time results in less convection and radiation heat losses through the walls and roof.

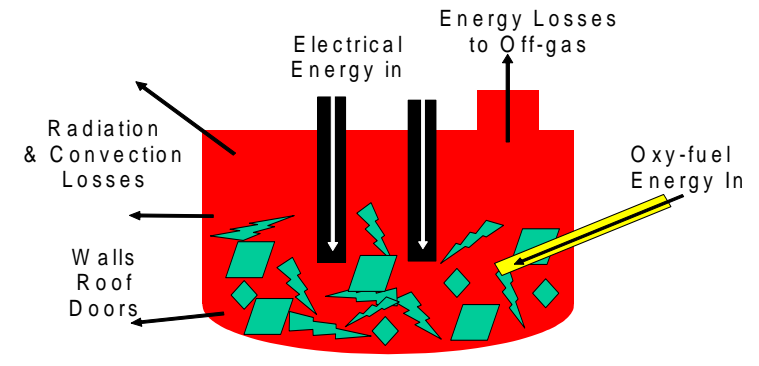

a)

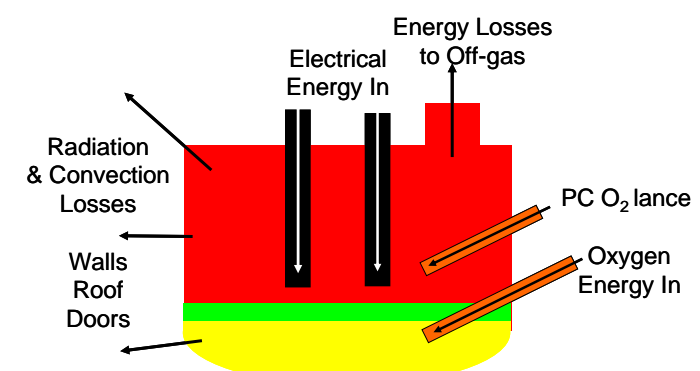

b)

Figure 11 Energy use and losses in an EAF (a) during melting and (b) flat bath

Once the scrap has melted and the electrodes are operating on an open bath in air (see Figure 11b), the electrical energy efficiency drops significantly because a significant portion of the arc energy is reflected from the arc and bath surface to the sidewalls and roof where the energy is lost in heating (and often melting) refractory rather than steel. Therefore, opportunities to increase the energy efficiency are greatest during this period. Figure 12 illustrates the efficiency differences during the different production periods with $\sim 85 \%$ electrical efficiency during the melting period dropping to $\sim 30 \%$ when arcing on a flat bath (correction period). Supplementary chemical energy in the form of additional oxygen can: a) combust $C$ to $C O$, b) post-combust the $\mathrm{CO}$ to $\mathrm{CO}_{2}$ in the furnace and c) recover the exothermic heat from the oxidation reactions. This decreases the time the steel is in the furnace reducing the energy losses and the electrical energy consumption. In addition, injecting small amounts of fine carbon with oxygen into the slag forms a foamy slag which blankets the arc and bath decreasing the losses to the side walls and roof. This provides the potential of further increases in electrical arc efficiency by utilizing more energy efficient long arcs (higher voltage and lower current) on a flat bath. Co-jet technology provides a supersonic oxygen jet with the opportunity of adding carbon directly into the jet providing a foamy slag effectively increasing chemical energy and decreasing radiation losses to the sidewalls. This section of the report will evaluate the effectiveness of the Co-Jet system on productivity and efficiency of a steel foundry. 


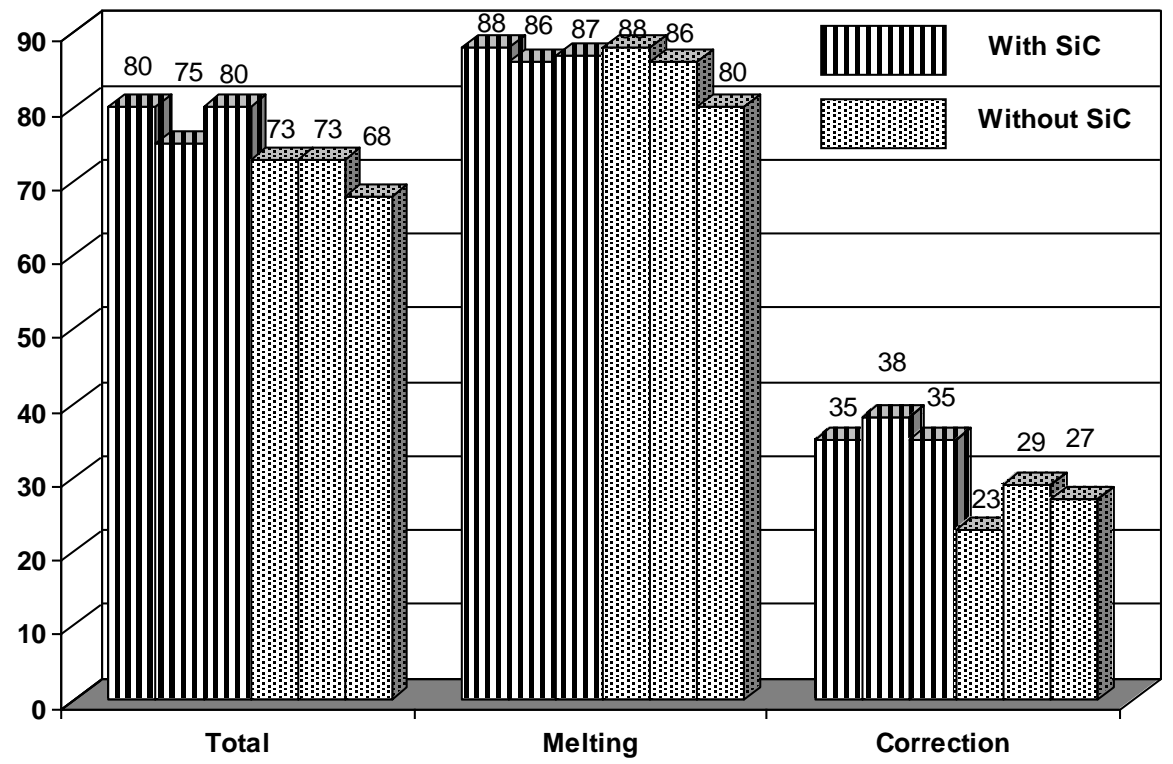

Figure 12 Total and operational energy efficiency for heats with and without $\mathrm{SiC}$

The participating foundry installed a door oxy-fuel burner and sidewall Co-Jet in one of their 20 ton capacity basic EAFs in late 2007. The energy and productivity were compared for approximately 600 heats produced before and after the installations. Figure 13 and Table 7 compare the electrical energy consumption on a per ton basis for production before and after the installation. The oxy-fuel/co-jet practice decreased the average electrical consumption by 49 $\mathrm{kWh} / \mathrm{t}(10 \%)$. The large standard deviation indicates the effect of delays on the energy consumption. Heats with no delays were consistently low in energy consumption (between 400 and $420 \mathrm{kWh} / \mathrm{t}$ ) indicating potential savings of $20 \%$ with chemical energy with more efficient scheduling and preventive maintenance to avoid delays in the furnace.

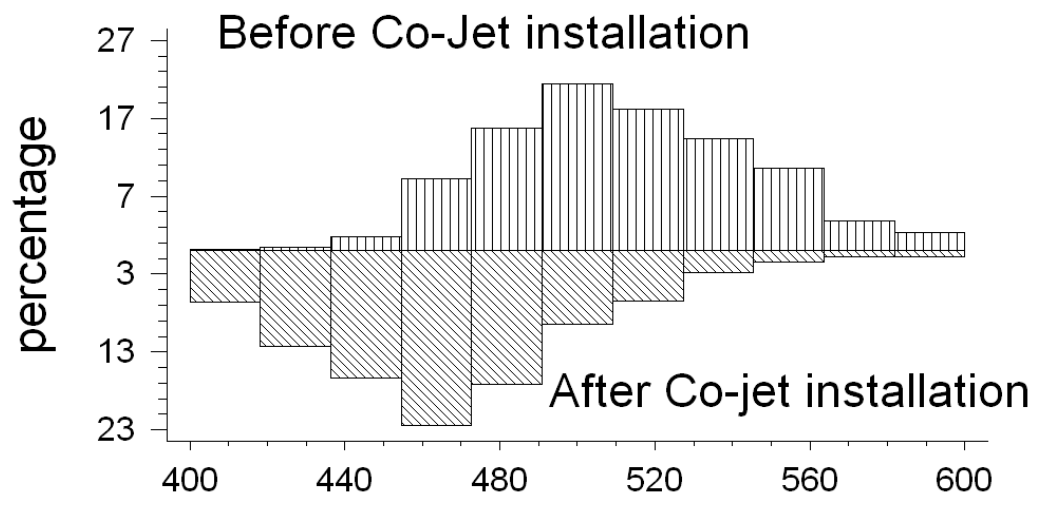

Figure 13 Electrical energy use (in kWh/ton) with oxy-fuel burner/Co-Jet in 20t EAF

Table 7 Electrical energy consumption in 20t basic EAF with oxy-fuel burner and Co-Jet

\begin{tabular}{|c|c|c|}
\hline & Before changes & After changes \\
\hline Number of heats evaluated & 627 & 561 \\
\hline Mean $(\mathrm{kWh} / \mathrm{t})$ & $\mathbf{5 1 3 . 9}$ & $\mathbf{4 6 4 . 8}$ \\
\hline Standard deviation $(\mathrm{kWh} / \mathrm{t})$ & 37.7 & 47.0 \\
\hline
\end{tabular}


Melt-down time (time from first power on until the scrap was completely melted $=$ flat bath) was decreased by $15 \%$ with the addition of the oxy-fuel and Co-Jet. There is potential for up to a $30 \%$ decrease in the melting time based on the typical times measured during heats observed during the industrial trials. The total heat time (from charging to tap) was compared before and after the oxy-fuel/Co-Jet installation in Figure 14 and Table 8 . The average total heat time decreased by 22 minutes (15\%) when using the oxy-fuel/Co-Jet practice. There is potential for significant additional heat time savings based on one of the trial heats in which the total heat time was 110 minutes, nearly $40 \%$ less than the average time before the oxy-fuel Co-Jet installation. Sufficient detailed cost information was not provided by industrial partners to accurately calculate a return on investment.

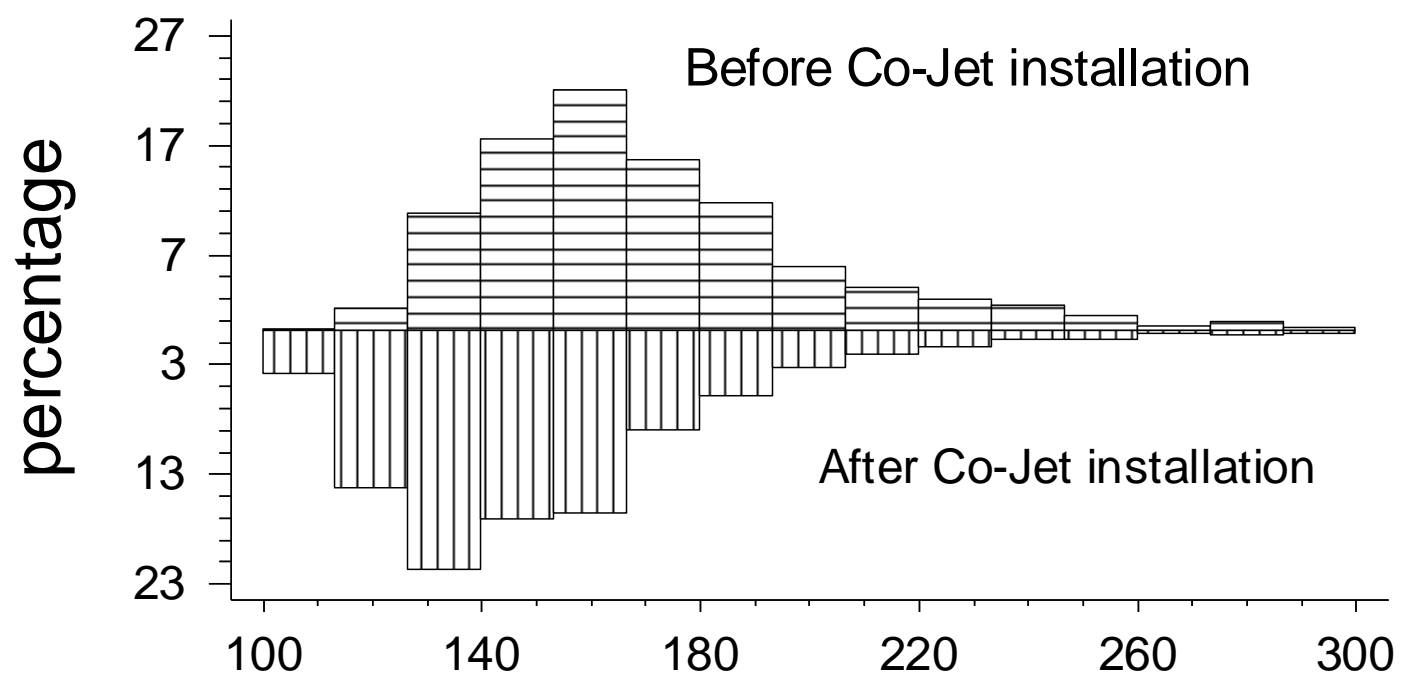

Figure 14 Total heat time (in $\mathrm{min}$ ) for a 20t basic EAF with oxy-fuel/Co-Jet

Table 8 Statistics for total heat time (in minutes) for 20t basic EAF with oxy-fuel/Co-Jet

\begin{tabular}{|c|c|c|}
\hline & Before Co-Jet & After Co-Jet \\
\hline Number of heats in study & 627 & 561 \\
\hline Average heat time (min) & $\mathbf{1 7 6}$ & $\mathbf{1 5 4}$ \\
\hline Standard deviation (min) & 51 & 38 \\
\hline Best time (min) & & $\mathbf{1 1 0}$ \\
\hline
\end{tabular}

\subsection{5 - Industrial Ladle Trials Using Lightweight Low Thermal Conductivity Lining}

The goal of this part of the research was to run an industrial trial using a lightweight low thermal conductivity alumina lining to determine the benefits/challenges of this material in a production foundry. For the industrial trial, a partnering foundry provided a shank ladle of 750 lbs (liquid steel capacity). The ladle was prepared in the Missouri S\&T laboratories before being transported back to the foundry for use. The dimensions of the steel shell were 18 " internal diameter and 22" height.

In the trial, a commercially available, low thermal conductivity and relatively low density alumina based castable lining was utilized. The material is cement bonded and has very effective insulating properties due to its microporosity. The thermal conductivity of the new material (approximately $0.9 \mathrm{~W} / \mathrm{m}^{\circ} \mathrm{K}$ ) is less than common alumina castables (around $2.4 \mathrm{~W} / \mathrm{m}^{\circ} \mathrm{K}$ ). The 
thermal efficiency was further enhanced by using an additional outside insulating lining made from a very low thermal conductivity, light weight material. The combination of the outside insulating lining and inner microporous alumina castable is denoted as the "sandwich lining". The properties of the sandwich lining in comparison to standard alumina castable are given in Table 9.

Table 9 Properties of lining materials

\begin{tabular}{|c|c|c|c|}
\hline \multirow[b]{2}{*}{ Properties } & \multicolumn{2}{|c|}{ Sandwich } & \multirow[b]{2}{*}{$\begin{array}{l}\text { Common } \\
\text { castable }\end{array}$} \\
\hline & $\begin{array}{c}\text { Insulating } \\
\text { lining }\end{array}$ & $\begin{array}{c}\text { Commercial } \\
\text { lightweight } \\
\text { castable }\end{array}$ & \\
\hline Density, $\mathrm{kg} / \mathrm{m}^{3}$ & 235 & 1600 & 2300 \\
\hline Thermal conductivity, $\mathrm{W} / \mathrm{m}^{\circ} \mathrm{K}$ & 0.17 & $0.5-0.9$ & $2.1-2.4$ \\
\hline Max. Service Temp., ${ }^{\circ} \mathrm{C}$ & 1100 & 1650 & N/A \\
\hline Composition & $\begin{array}{l}47 \% \mathrm{SiO}_{2}, \\
45 \% \mathrm{CaO}\end{array}$ & $\begin{array}{c}85-87 \% \mathrm{Al}_{2} \mathrm{O}_{3} \\
13-14 \mathrm{CaO}\end{array}$ & $\begin{array}{c}69 \% \mathrm{Al}_{2} \mathrm{O}_{3}, \\
26 \% \mathrm{SiO}_{2}\end{array}$ \\
\hline
\end{tabular}

The effective properties of the sandwich type lining which consisted of layers made from a lightweight castable and an insulating lining with a thickness fraction $x_{i}$ were estimated under following rules:

- Effective density with the rule of mixtures:

$$
\rho=\sum_{i} \rho_{i} x_{i}
$$

- Effective coefficient of thermal conductivity $(k)$ from equivalent heat flux:

$$
k=\frac{1}{\sum_{i} \frac{x_{i}}{k_{i}}}
$$

An effective density of $1.36 \mathrm{~g} / \mathrm{cm}^{3}$ and an effective thermal conductivity of $0.37 \mathrm{~W} / \mathrm{m}^{\circ} \mathrm{K}$ were calculated for the sandwich lining using equation 1 and 2, respectively based on 2" thickness of castable and 0.5 " thickness of insulation lining. The results are also displayed in Figure 15, which shows that the combination of the commercial and insulating linings provides a lower thermal conductivity and density when compared to commonly $70 \%-90 \%$ alumina castable linings.

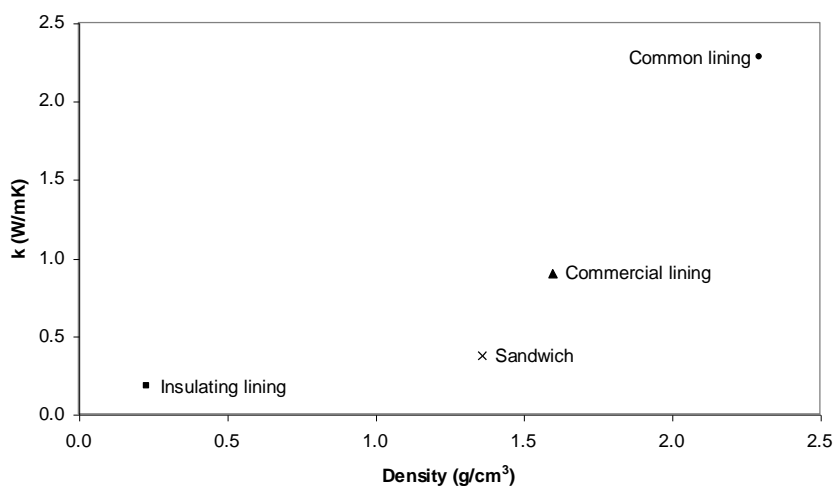

Figure 15 Thermal conductivity and density of lining materials 
In the trial, the insulating lining was placed between the steel shell and castable lining. The insulating refractory was supplied in the form of 36 " x 12 " x 4 " thick boards and were cut $1 / 2$ " thick to assemble the sides of the actual ladle and 1" thick to accommodate the bottom (see Figure 16a). Mortar was used to attach the insulating slices to the shell. Preliminary tests showed that the commercial lining undergoes a fast set time at the moment of pouring, which can be solved by adding a set-retarder. Therefore, a set-retarder was added to the castable material during mixing. The ladle was set on a portable stinger vibrator to help flowability of material and the ladle was cast (See Figure 16b).

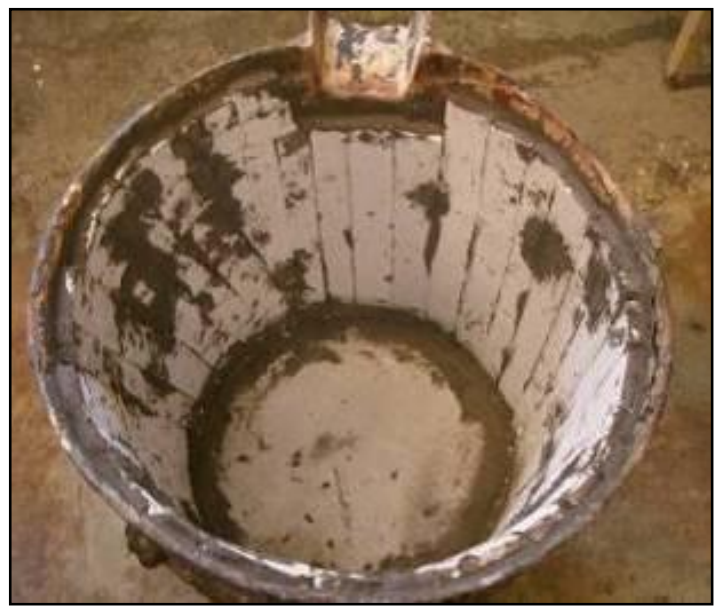

a)

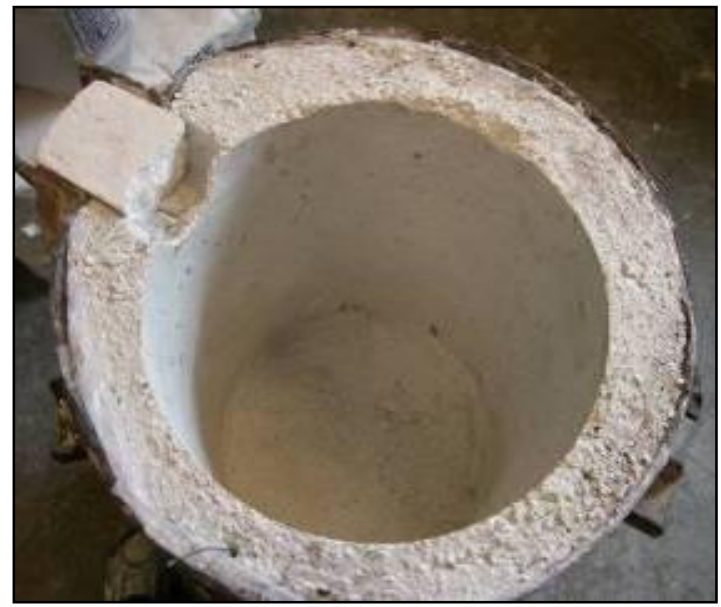

b)

Figure 16 a) Insulation lining inside the steel shell b) ladle with cast commercial lining

The refractory surface was gradually heated to a final soak temperature of $2460^{\circ} \mathrm{F}\left(1350^{\circ} \mathrm{C}\right)$ over five hours. Thermal images were captured during the process using an infrared camera and showed that the steel shell temperature varied between $346^{\circ} \mathrm{F}\left(174^{\circ} \mathrm{C}\right)$ towards the bottom of the ladle and $513^{\circ} \mathrm{F}\left(267^{\circ} \mathrm{C}\right)$ on the sidewalls. Overall, the shell temperature was significantly lower in temperature when compared to the same size ladle made from standard alumina $\left(400-500^{\circ} \mathrm{C}\right)$ indicating improved insulation. The ladle was slow cooled to $200^{\circ} \mathrm{F}\left(97^{\circ} \mathrm{C}\right)$ over eight hours. The ladle was coated with a refractory mortar before use and sent to the participating foundry. At the foundry, the ladle was preheated using a vertical gas preheater to an inside temperature of approximately $1879^{\circ} \mathrm{F}\left(1026^{\circ} \mathrm{C}\right)$ as measured with the IR camera. The shell temperature of the pre-heated ladle averaged $328^{\circ} \mathrm{F}$, significantly less when compared $820^{\circ} \mathrm{F}$ when using common alumina castable and pre-heated in the same way indicating significantly lower energy losses with the new sandwich refractory.

Each heat was tapped from one to four times (depending on furnace capacity and charge weight) into the ladle for pouring. The molten steel temperature was collected from six ladles poured using the sandwich refractory and averaged and compared to the average temperatures from multiple heats poured with the same ladle using common alumina castable (Figure 17). The sandwich type lining averaged a total temperature loss of $95^{\circ} \mathrm{F}$ from the furnace tap temperature to the ladle temperature after 5 minutes of hold time. This is significantly less than the average temperature loss of $155^{\circ} \mathrm{F}$ after 5 minutes of hold time for common alumina castable ladles. The energy loss through the sidewalls is reduced by $40 \%$ with the sandwich lining when compared to common alumina castable linings. A reduction in the tap temperature of $60^{\circ} \mathrm{F}$ would save $10-15$ $\mathrm{kWh} / \mathrm{t}(\sim 3 \%$ of energy) based on the low efficiency of electric furnaces in increasing the 
temperature for tap. Exact costs of the new refractory material were unable to be determined, as much of the material was donated or purchased in small quantities. Initial estimates are that costs would be a small percentage increase depending on current lining type.

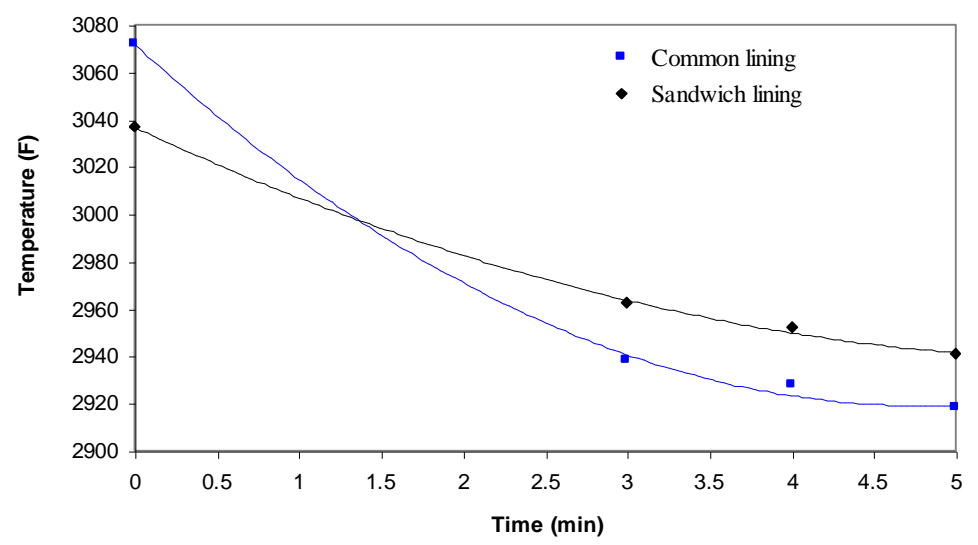

Figure 17 Steel temperature in castable alumina ladle and sandwich lining during holding

\subsection{TASK 5 - Laboratory study of factors affecting energy consumption during melting in foundries.}

\subsection{1 - New refractory applications to reduce ladle losses}

Effective ladle design is important for steel casting production. In foundry operations, the temperature of the liquid steel in the ladle is typically $150^{\circ} \mathrm{F}$ to $300^{\circ} \mathrm{F}$ above the steel's melting point to compensate for the heat losses in small ladles and the associated high cooling rates from the large surface area to volume ratios. High superheat is also necessary to provide sufficient steel fluidity to properly fill the mold cavity. In spite of the relatively short time that the steel is in contact with the ladle lining, the huge thermal gradients in the lining drive high values of heat transfer through the refractory surface. Steel foundry ladles vary in capacity from 400 to 50,000 lbs as summarized in Figure 18a. As the ladle capacity decreases, the lining surface area per lb of liquid metal increases (see Figure 18b). This is important because heat transfer is directly proportional to the surface area. For example, small ladles $(<1000 \mathrm{lb})$ have five times the surface area per ton as large ladles $(>20,000 \mathrm{lb})$ and therefore would experience five times the rate of temperature loss under similar ladle conditions (tap temperature, preheat, refractory types and thicknesses, etc.).

Heat transfer between the liquid metal and the ladle lining as well as the associated heat losses in foundry linings were analyzed using data generated at 20 steel foundries and from industrial measurements completed at seven foundries. Temperature measurements were made using thermocouples and infrared cameras. Figure 19a shows a general trend of increasing tap temperatures with decreasing ladle capacity. Higher tap temperatures help compensate for the much higher rate of steel temperature loss in smaller ladles (Figure 19b). The cooling rate of the liquid steel through the ladle lining decreases exponentially based on increasing ladle size. 


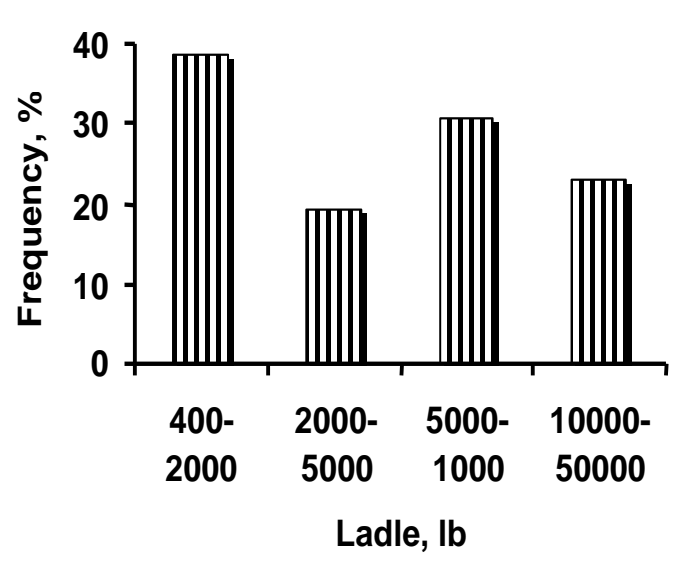

a)

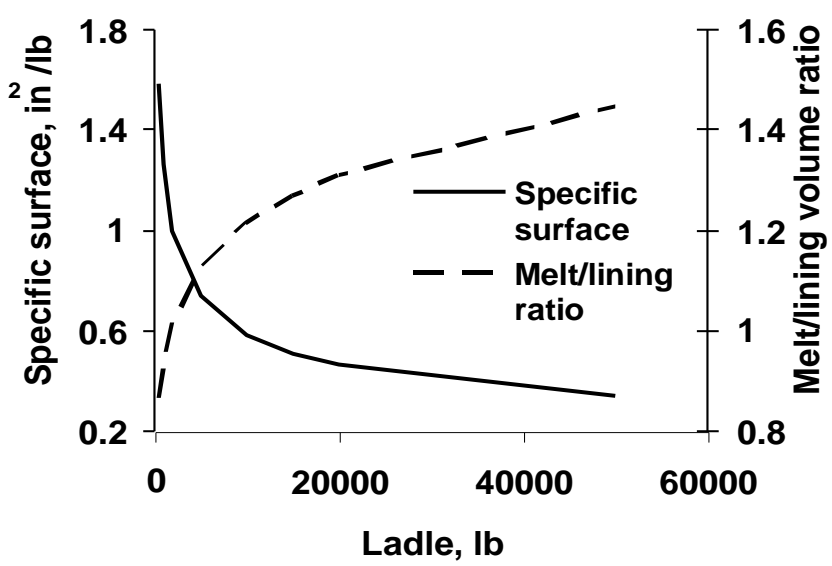

b)

Figure 18 Distribution of a) steel foundry ladle size and b) lining surface/melt weight ratio

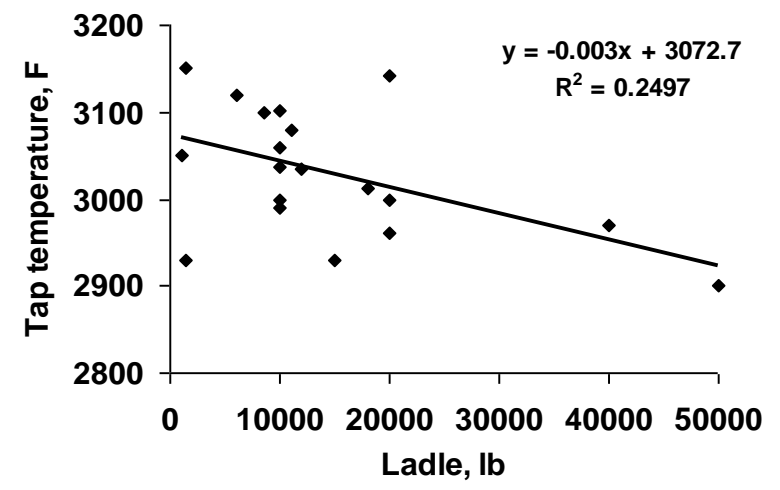

a)

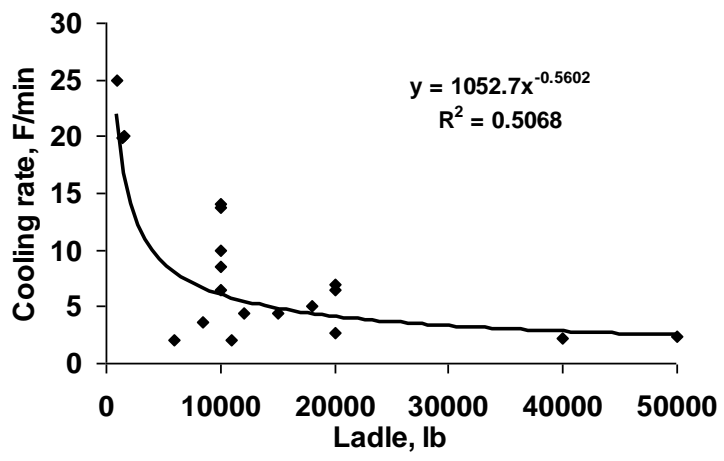

b)

Figure 19 Effect of ladle capacity on a) tap temperature and b) rate of temperature loss

The temperature losses in the industrial ladles were also modeled using FLUENT, a commercial computational fluid dynamic software package. It was found that the results predicted by the FLUENT ladle model were very similar to the results observed in industrial foundries. The ladle size was shown to have a major influence on the rate of liquid steel temperature drop because foundry ladles are typically not at steady state (heat is not fully soaked into the lining) resulting in larger heat losses to compensate for heat accumulation in the lining (see Figure 20a). Figure $20 \mathrm{~b}$ compares the different mechanisms of heat loss (lining accumulation versus radiation) while holding liquid steel in the ladle. Radiation losses could be minimized by using radiation protection devices (lid, special melt cover, etc.). Reduction in lining accumulation losses requires either lower thermal conductivity materials or much more effective ladle preheating. 


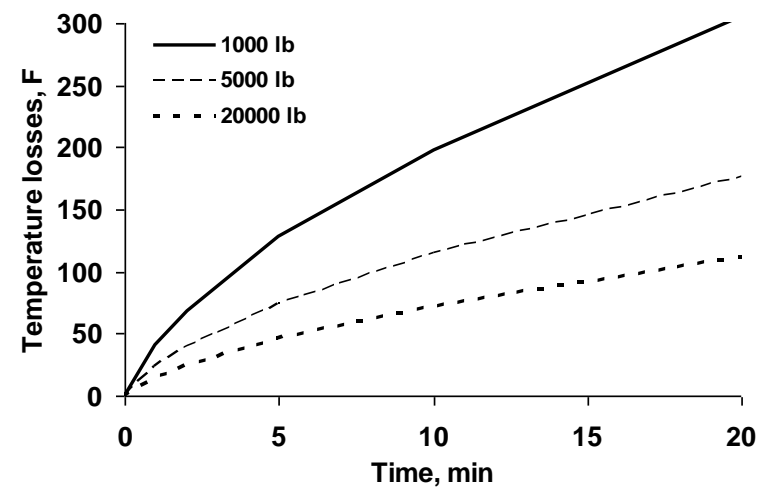

a)

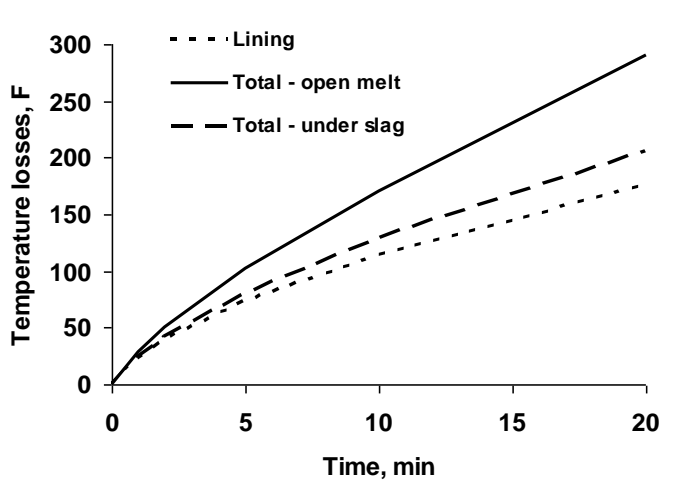

b)

Figure 20 a) Influence of ladle capacity on temperature losses during holding and b) temperature loss by lining accumulation and radiation from top surface of $5000 \mathrm{lb}$ ladle

Some foundries tap the furnace into a large transport ladle which is used to pour shank type small capacity ladles. This more than doubles the melt lining exposure significantly increasing the magnitude of temperature losses. For example, one medium carbon and low alloy steel foundry melting in a 5 ton EAF, taps steel at $3100^{\circ} \mathrm{F}$ into an $11,000 \mathrm{lb}$. alumina lined teapot ladle preheated to $1955^{\circ} \mathrm{F}$. The steel is re-ladled into a $1000 \mathrm{lb}$. shank ladle with a lining consisting of low thermal conductivity magnesia boards surrounded by dry sand to pour medium and small size castings. An example of the temperature losses during tap, while holding in the teapot ladle and in the re-ladled steel are given in Figure 21a. During the 30 minute pouring time, the total temperature loss was $280^{\circ} \mathrm{F}$ to $300^{\circ} \mathrm{F}$. Infrared images of the teapot and shank ladles with liquid steel are given in Figures $21 \mathrm{~b}$ and 21c.

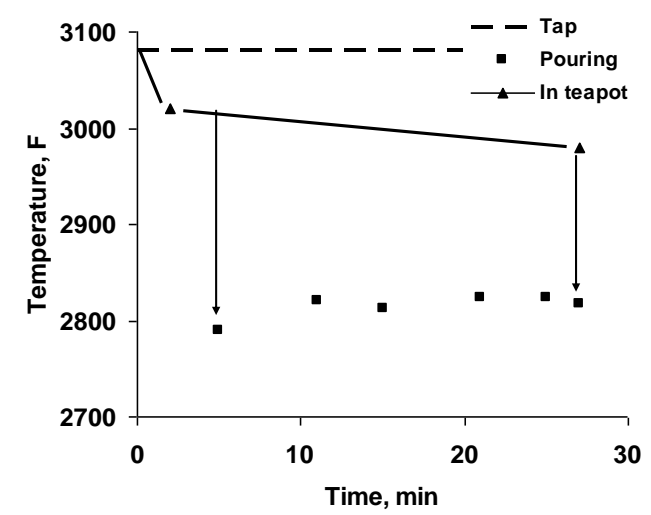

a)

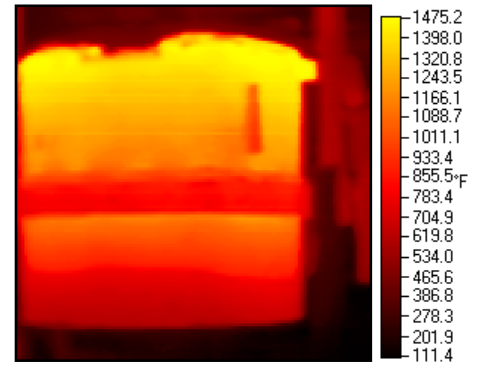

b)

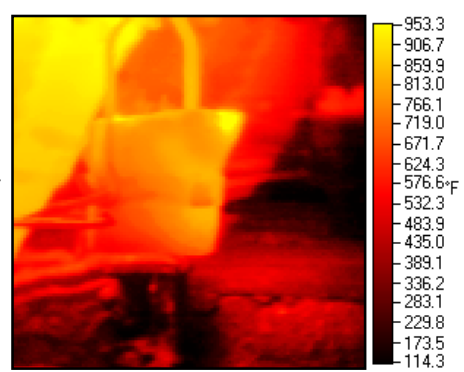

c)

Figure 21

a) Temperature of steel in 11,000 lb teapot ladle and 1,000 lb pouring ladle,

b) surface of preheated alumina-lined 11,000 lb teapot ladle (before tap), and

c) surface of empty $1000 \mathrm{lb}$ shank ladle (lined with low density magnesia lining)

The large temperature losses associated with the use of foundry ladles led to Missouri S\&T's research in developing new lining materials designed especially for steel handling in foundries. This section of the report outlines the development of these new lining materials. A basic alumina castable was reduced in density by adding alumina hollow spheres and calcium aluminate cement binder. In contrast to conventional alumina aggregates with density range from 3.5 to $3.7 \mathrm{~g} / \mathrm{cm}^{3}$, hollow alumina aggregates have a density range from 0.5 to $0.8 \mathrm{~g} / \mathrm{cm}^{3}$ and 
provide pores from 500 to $1500 \mu \mathrm{m}$ in size. It is this aggregate substitution that imparts the first level of porosity to this insulating castable. In order to render the castable foamable, additional matrix powders are required. In this case, ultrafine hydrateable alumina, calcined alumina, and calcium aluminate cement are added to lower the particle size distribution modulus and to provide the requisite fines as well as additional binder for the system. After charging the basecastable and additional fines into a paddle type mixer, it is tempered with enough water to allow the system to be characterized as an excellent vibratable or borderline self-flow castable. At this moment, three surface active agents are introduced and the paddle blade is switched to a whisk attachment in order to facilitate air incorporation and the foaming process. Also added at this time is an engineered fugitive of organic microspheres with an average particle size of $20 \mu \mathrm{m}$. This very low mass organic material volatilizes upon the initial heating of the castable leaving fine spherical porosity. The specific volume of the castable is increased dramatically during the mixing/foaming process. The prepared insulating castable material was then pre-cast into a plastic mold. Since the binder for this system is hydratable, the castable is treated similar to other castable materials in terms of maintaining a warm and humid environment for setting and curing.

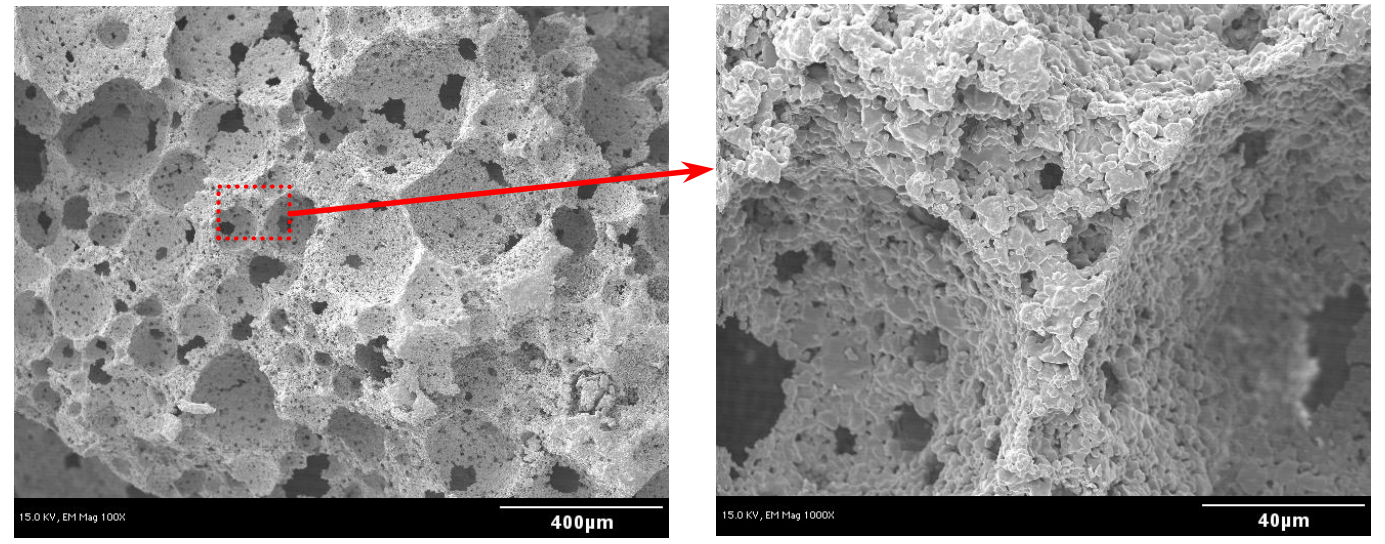

Figure 22 SEM images of a foamed insulating castable fracture surface

A bulk density of less than $1 \mathrm{~g} / \mathrm{cm}^{3}$ and porosity levels in excess of $75 \mathrm{vol} \%$ has been achieved. Figure 22 is a scanning electron microscope image of a typical fracture surface of the foamed castable. The largest pores in the system are due to hollow alumina sphere aggregate (not shown in Figure 22). The second level of porosity (Figure 22a) is due to air incorporated during the foaming process. These pores range in size from 50 to $500 \mu \mathrm{m}$ and account for the vast majority of the porosity in the system. The third level of porosity (Figure 22b) results from the engineered organic fugitive material and has an average pore size of about $20 \mu \mathrm{m}$.

Three types of lining materials were studied (see Table 10), a regular alumina based castable, a low density magnesia ladle insert, and a newly developed low density porous alumina castable. All materials were tested as a prefabricated insert with 1" thickness for a ladle of approximately 100 lbs capacity. The low density magnesia insert was used in the supplied condition while the inserts from two castable ceramics were poured into special plastic molds which were replicated from one of the commercial magnesia inserts. This resulted in all tested inserts being the same shape (Figure 23). The castable inserts were fired to $1400^{\circ} \mathrm{C}$. Nine thermocouples were installed at different wall positions (inside, outside and in the middle) at three levels (upper, central and lower sidewall). In addition, three thermocouples were installed in the bottom (see Figure 24a). The insert with thermocouples was installed into a steel shell with approximately 1" dry sand layer surrounding the insert (Figure 24b). A National Instrument Data Acquisition System was 
used for data collection. Cast iron was melted to increase the possible holding time in the ladle without having solidified metal. The metal was superheated to $1650^{\circ} \mathrm{C}$ in an induction furnace and tapped into the ladle. The ladle was held until the temperature reached a minimal temperature of $1330^{\circ} \mathrm{C}$.

Table 10 Three types of lining materials studied

\begin{tabular}{|l|c|}
\hline \multicolumn{1}{|c|}{ Ceramics } & Density, $\mathrm{kg} / \mathrm{m}^{3}$ \\
\hline Alumina castable & 2300 \\
\hline Low density magnesia crucible & 1400 \\
\hline Porous alumina castable & $900-950$ \\
\hline
\end{tabular}

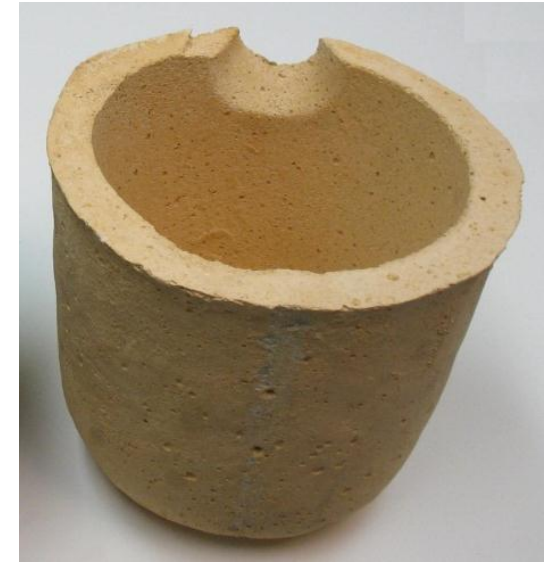

a)

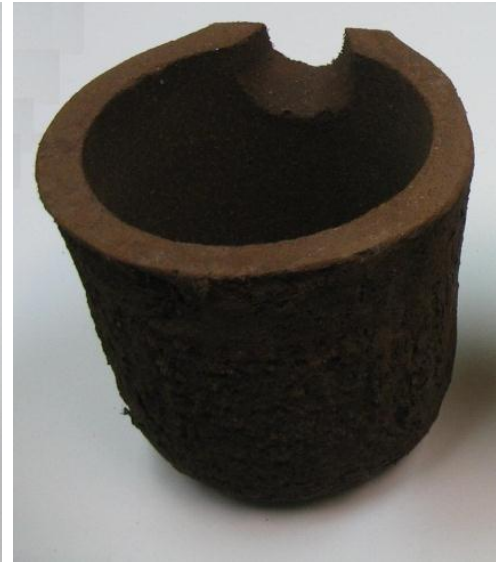

b)

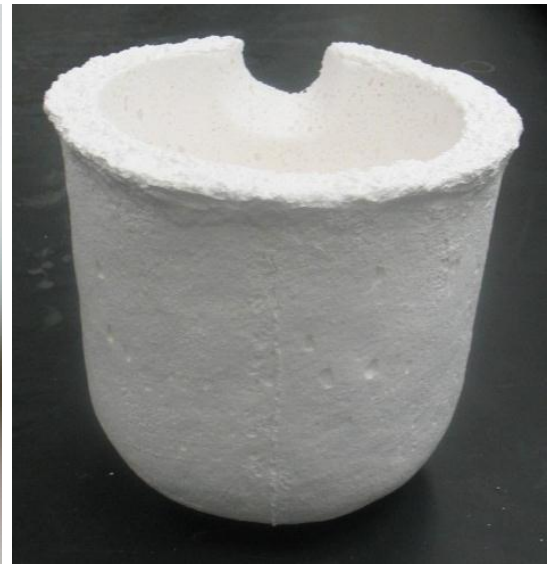

c)

Figure 23 a) Standard alumina castable, b) low-density magnesia and c) new alumina castable

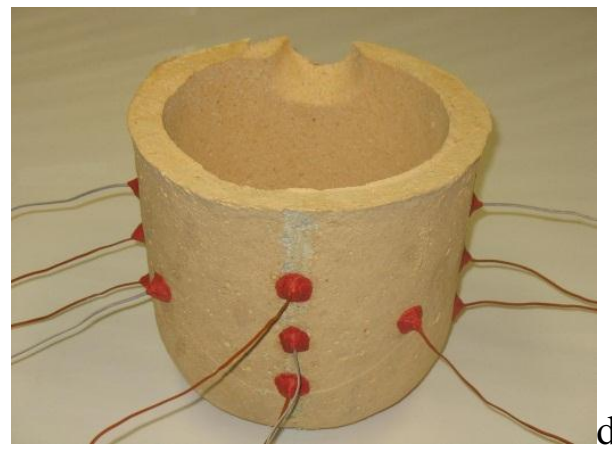

a)

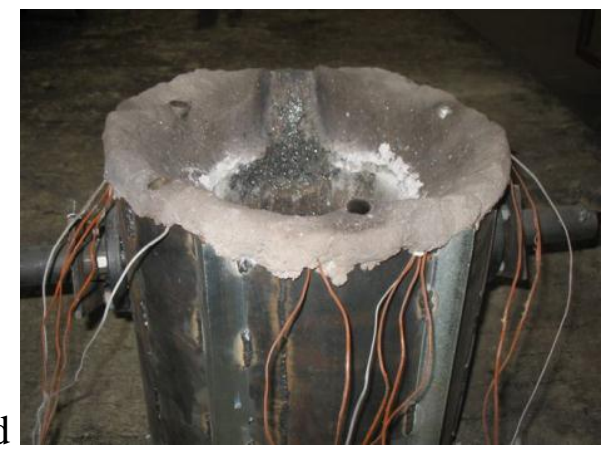

b)

Figure 24 a) Insert with thermocouples and b) ladle with insert and thermocouples

Experimental data showed that the newly developed porous ceramic material has a thermal conductivity that is 2.2 to 2.8 times lower than regular alumina castable with more stable properties than low density magnesia boards (see Figure 25a). Typically, low density materials are able to produce lower thermal conductivity but suffer from poor mechanical properties of the ceramics. The thermal conductivity of the various linings as measured in the Missouri S\&T labs versus density is given in Figure 25b. The newly developed alumina porous castable lining has a low density but possesses much higher strength and thermal stability than the magnesia boards. 


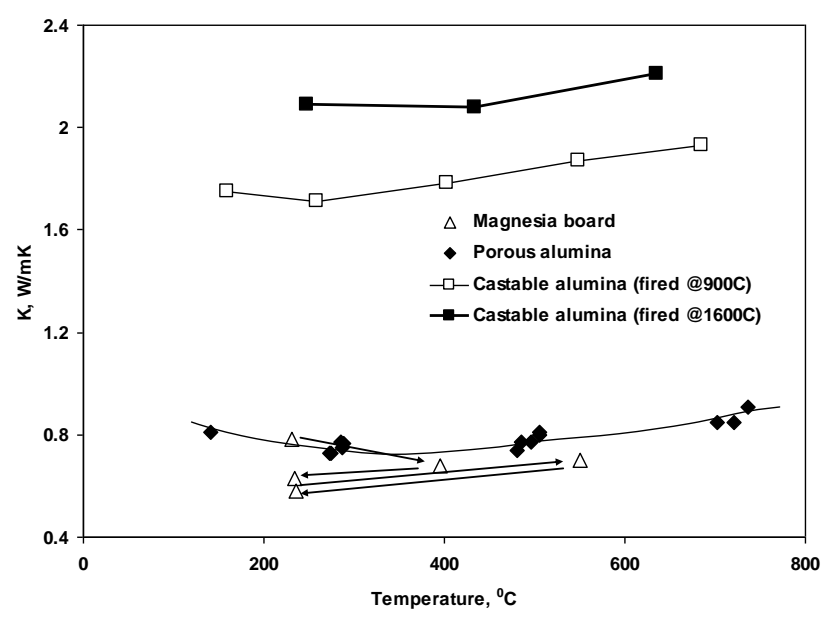

a)

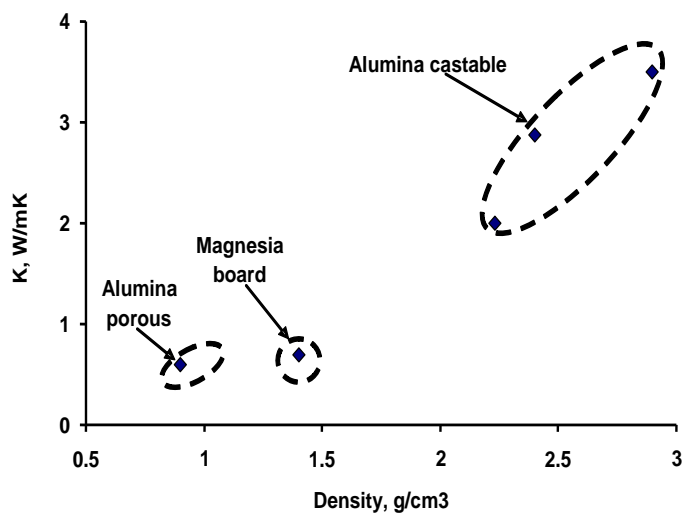

b)

Figure 25 Effect of a) lining temperature and b) lining density on lining thermal conductivity

Each of the three different types of ceramic ladle linings were inserted in the test ladle and surrounded by a 1" thickness of dry sand and tested under similar conditions to industrial foundries. The metal was tapped in each case at $1630^{\circ} \mathrm{C}$ into the test ladles. Both castable alumina ladle linings (solid and porous) were preheated with a $\mathrm{SiC}$ electrical preheater to $700^{\circ} \mathrm{C}$ internal surface temperature for 2 hours. The differences in the physical properties of the linings had a significant influence on the liquid metal temperature losses while holding in the ladle. Figure 26 compares the effect that the three different lining types would have on the liquid metal temperature in the $100 \mathrm{lb}$ ladle modeled using FLUENT. The results of the modeling are also compared with experimental results in Table 11.

Table 11 Ladle holding time for melt temperature to drop from $1600^{\circ} \mathrm{C}$ to $1350^{\circ} \mathrm{C}$

\begin{tabular}{|c|c|c|c|c|}
\hline \multirow[t]{2}{*}{ Lining } & \multirow[t]{2}{*}{ Preheat, ${ }^{\circ} \mathrm{C}$} & \multirow[t]{2}{*}{$\begin{array}{l}\text { Measured time } \\
\text { experimental, min }\end{array}$} & \multicolumn{2}{|c|}{$\begin{array}{l}\text { Calculated time using } \\
\text { FLUENT model, min }\end{array}$} \\
\hline & & & Open top & Isolated top \\
\hline Alumina castable & 700 & 7 & 5 & 10 \\
\hline Low density magnesia board & No preheat & 9 & 7 & 13 \\
\hline Alumina porous castable & 700 & 18 & 12 & 30 \\
\hline
\end{tabular}

Figure 26 illustrates three fields representing the possible variations in time and temperature depended on the type of ladle materials and ladle procedure (with or without thermal isolation of top melt surface). This variation was used because of the wide variation in ladle practices encountered in the foundry industry. The alumina castable lining and the newly developed porous castable lining were both used after preheating to $700^{\circ} \mathrm{C}$ because most foundries would preheat these types of ladles. However, the magnesia boards were used at room temperature initially because these materials were not designed for intensive preheat. Figure 26 illustrates that room temperature magnesia board ladles do have some advantages when compared to preheated alumina castable ladles. However, the newly developed porous alumina ceramics provide the possibility of cutting the temperature losses in one-half, effectively doubling the possible metal holding time in the ladle. The new porous lining is less sensitive to the preheat condition than normal castable linings. 


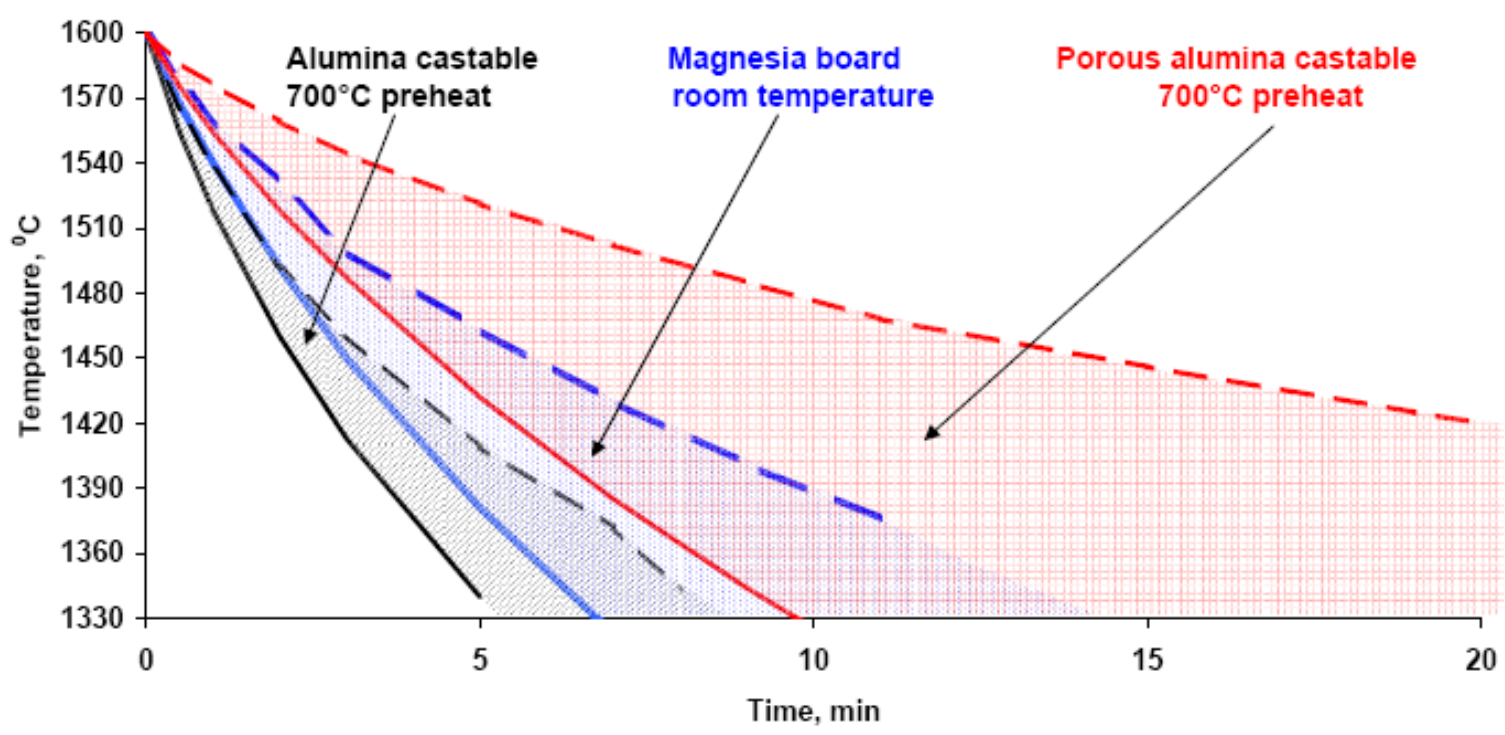

Figure 26 Comparison of melt temperature losses in the ladle with different linings (solid line-open liquid surface and dotted line-no radiation through liquid surface)

Experimental data combined with FLUENT model results provides the possibility to model industrial ladles under different refractory lining and metal handling conditions. For example, Figure 27 illustrates the temperature profiles using the FLUENT model for $1000 \mathrm{lb}$ ladles with an open melt surface covered by a thin layer of slag. In this case, four lining conditions were compared to calculate the required tap temperature to pour after 12 minutes of handling time at a final pouring temperature of $2840^{\circ} \mathrm{F}$. The highest tap temperature $\left(3275^{\circ} \mathrm{F}\right)$ was required for a traditional castable alumina lining preheated to at least $1500^{\circ} \mathrm{F}$ to compensate for the heat losses in the ladle. Low density magnesia boards require a lower tap temperature $\left(3200^{\circ} \mathrm{F}\right)$ with less variation in the pour temperature based on differing ladle conditions. The tap temperature could be reduced to $3080^{\circ} \mathrm{F}$ for similarly constructed castable porous refractory, a significant decrease in temperature due to the reduced energy losses using this new material. The tap temperature could be reduced even further to $3040^{\circ} \mathrm{F}$ if the porous castable alumina lining is backed up by a lower conductivity (calcium silicate) backup material. This change is a total reduction in the tap temperature of $240^{\circ} \mathrm{F}$ from traditional alumina castable linings and could increase the holding time at the same tap temperature by at least $30 \%$. A reduction in the tap temperature of $240^{\circ} \mathrm{F}$ would save an estimated $55 \mathrm{kWh} / \mathrm{t}$ in electrical energy consumption $(\sim 10-15 \%$ based on the $\sim 50 \%$ efficiency at high temperature) or $\$ 3.85$ per ton (assuming $\$ 0.07 / \mathrm{kwh}$ ), off-setting the costs of the new refractories for most steel foundries. Actual savings depend on local electricity costs, current refractory costs and practices and ladle life. 


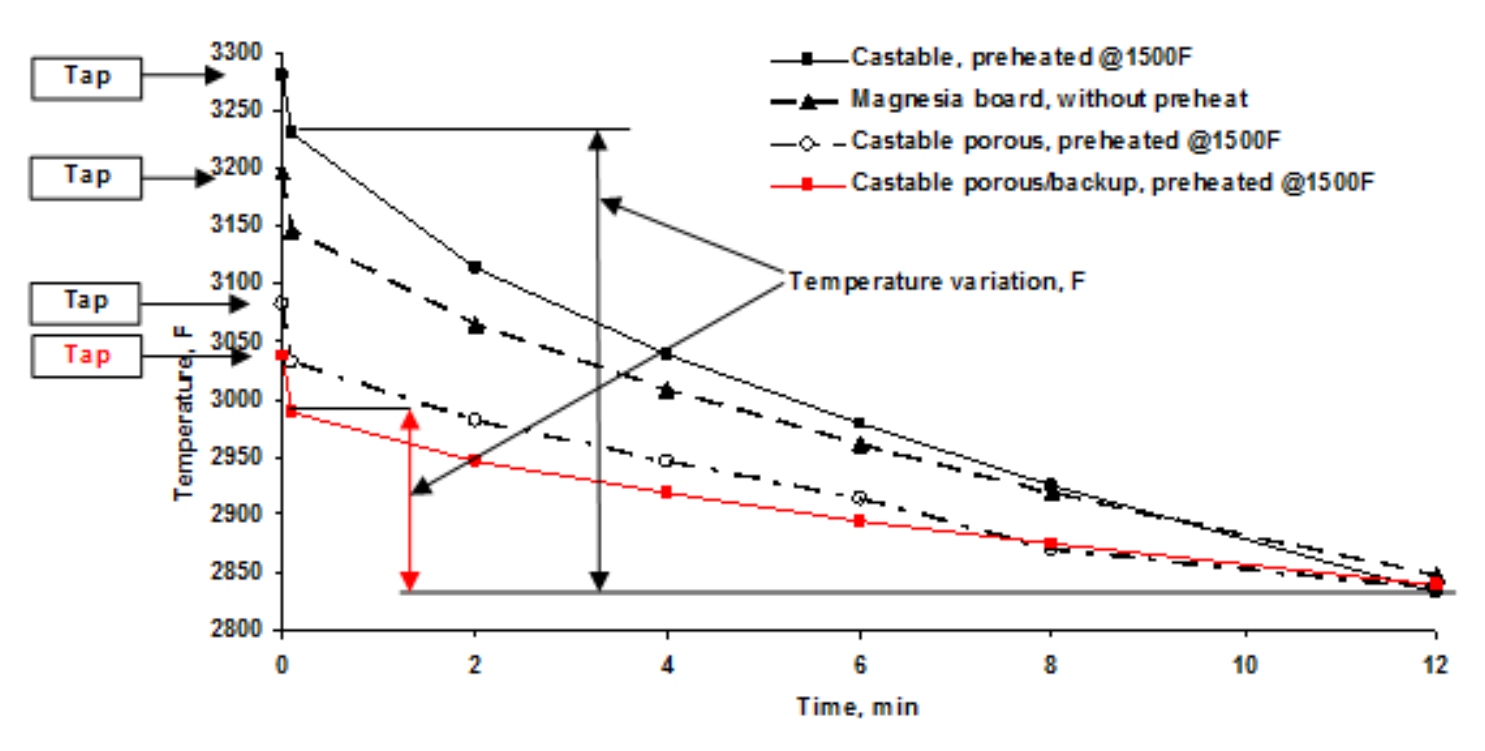

Figure 27 Required tap temperatures for pour temperature of $2840 \mathrm{~F}$ at 12 minutes after tap in $1000 \mathrm{lb}$ ladles lined with different refractories (FLUENT model)

In summary, this task focused on increasing the energy efficiency through the use of new ladle linings and improved melt handling processing for the steel foundry industry. The research was completed using a $100 \mathrm{lb}$ lab scale experimental ladle, FLUENT and FACTSAGE computer modeling, industrial measurements and statistics. A new ladle lining system developed (porous alumina castable working lining combined with a low-density calcium silicate backup lining) has proven to significantly decrease the heat losses of steel in the ladle resulting in an increase of up to $30 \%$ in the holding times and allowing tap temperatures to be decreased by as much as $240^{\circ} \mathrm{F}$ from traditional preheated high alumina castable ladle linings (actual savings depend on present ladle practices). The laboratory experimental data were incorporated into a computer model that predicts conditions in industrial foundry ladles.

\subsection{TASK 6 - Energy model of steel foundry melting operations.}

\subsubsection{Ladle model}

The aim of this task was to develop a tool to calculate and predict the temperature drop of molten steel during liquid steel handling from the furnace to the mold. The tap temperature must be high enough to meet the required mold pouring temperature and take into account temperature losses during tapping and holding. This energy model can be used to calculate the optimum melt superheat temperature in the melting furnace and decrease energy consumption.

Steel is melted and superheated in the furnace. Once the required tap temperature is reached, liquid steel is tapped into a ladle. In foundries, the ladle is used for holding and transporting the melt until pouring into the molds. During the holding period, temperature of the liquid steel continues to drop. The amount of drop depends on three major heat fluxes $(F)$ as illustrated in Figure 28:

- Flux 1 - radiation and alloying additions during tap

- Flux 2 - heat accumulated by lining and heat conducted through ladle walls

- Flux 3 - convection and radiation from top of the melt. 


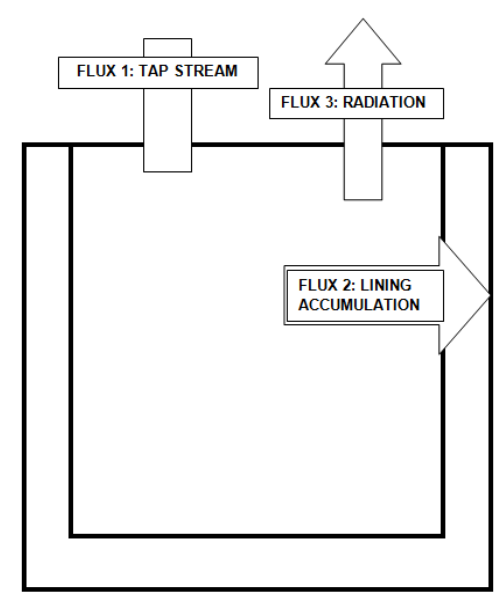

Figure 28 Heat losses from ladle during tapping and holding steel

The specific conditions for liquid steel in foundry ladles held for limited time (typically less than 30 minutes) can be described based on non-steady state heat transfer. However solving the nonsteady state heat transfer solvers (e.g. CFD using Fluent) is time consuming and not practical for use in industrial foundry on a day-to-day basis. To make the calculator more practical, nonsteady state heat fluxes were approximated and applied in the generalized heat balance:

$$
m c_{p} \Delta T=\sum_{i} F_{i} \Delta \tau
$$

$m, c_{p}$ and $\Delta \mathrm{T}$ are mass, specific heat capacity and temperature drop of liquid steel for time $\Delta \tau$.

Flux 1 (tap stream radiation) was calculated using the technique described in our paper ${ }^{6}$ and adopted in the EXCEL spreadsheet. Flux 2 (top surface radiation and convection losses) and Flux 3 (heat accumulated by lining) were determined using FLUENT CFD modeling by taking into consideration:

- $\quad$ effect of slag on radiation losses

- $\quad$ effect of cover (lid) on radiation losses

- $\quad$ thermal properties of lining materials

- ladle design (capacity, wall thickness)

- initial thermal conditions (pre-heating).

Meshes for different sized ladles were generated using Gambit software with two zones in the mesh (refractory and liquid steel). The lining properties were taken from previous work (see 3.4.1). Taking into consideration heat transfer between the melt and relatively low thermal conductivity lining, this boundary was considered as coupled (no temperature drop). The boundary conditions at the top of the liquid considered three cases: open top, slag layer and low thermal conductivity (kaowool) lid. Initialization (starting temperature distribution) was done for preheated and no preheat cases. For preheating, preliminary simulations were performed to determine the temperature field in preheated ladle. During use, the ladle was filled by liquid steel at a temperature of $1650^{\circ} \mathrm{C}\left(\sim 3000^{\circ} \mathrm{F}\right)$ and the simulation was completed for the various ladle top conditions. Simulation results were validated using industrial trial data. This validation allowed for simplification by reducing the number of variables. The lining surface heat flux was found to be independent of ladle size but depended on ladle refractory type and preheating conditions (Figure 29). 


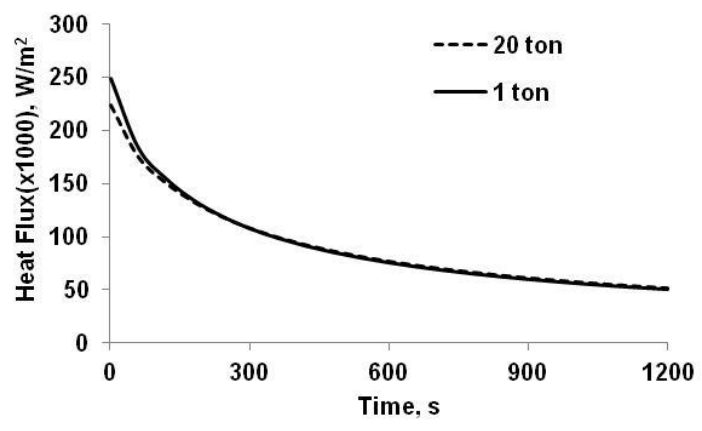

(a)

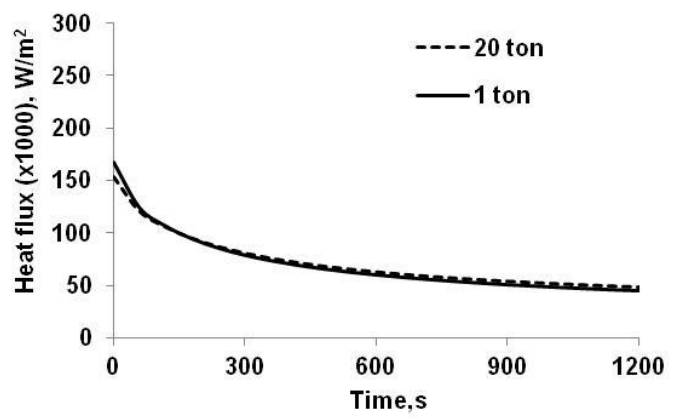

(b)

Figure 29 Heat flux from inside of a 20 ton and 1 ton ladle lining: a) - no preheated with $\mathrm{k}=1.5$ $\mathrm{W} / \mathrm{m}-\mathrm{K}$ and b) - preheated at $1200^{\circ} \mathrm{C}(2192 \mathrm{~F})$ for 2 hours with $\mathrm{k}=3 \mathrm{~W} / \mathrm{m}-\mathrm{K}$

\subsubsection{Ladle Model Validation}

Validation of the model is required to prove that it is applicable for industrial use. Five industrial trial cases (Table 12) were used to calculate the predicted temperature drop using the model and comparing it with the actual data. Figure 30 shows these comparisons with an $\mathrm{R}^{2}$ value of 0.86 showing acceptable correlation.

Table 12 List of industrial cases used for model validation

\begin{tabular}{|c|c|c|c|c|c|}
\hline & $\begin{array}{c}\text { Ladle capacity, } \\
\text { lbs }\end{array}$ & Tap Temp, F & $\begin{array}{c}\text { Holding time, } \\
\text { min }\end{array}$ & Refractory & Preheat, F \\
\hline Case 1 & 7000 & 3102 & 19 & Silica & No \\
\hline Case 2 & 400 & 3029 & 20 & Silica & 2000 \\
\hline Case 3 & 40000 & 3000 & 20 & Alumina & 1800 \\
\hline Case 4 & 18000 & 3000 & 10 & Alumina & 1600 \\
\hline Case 5 & 11000 & 3100 & 8 & Alumina & 1000 \\
\hline
\end{tabular}

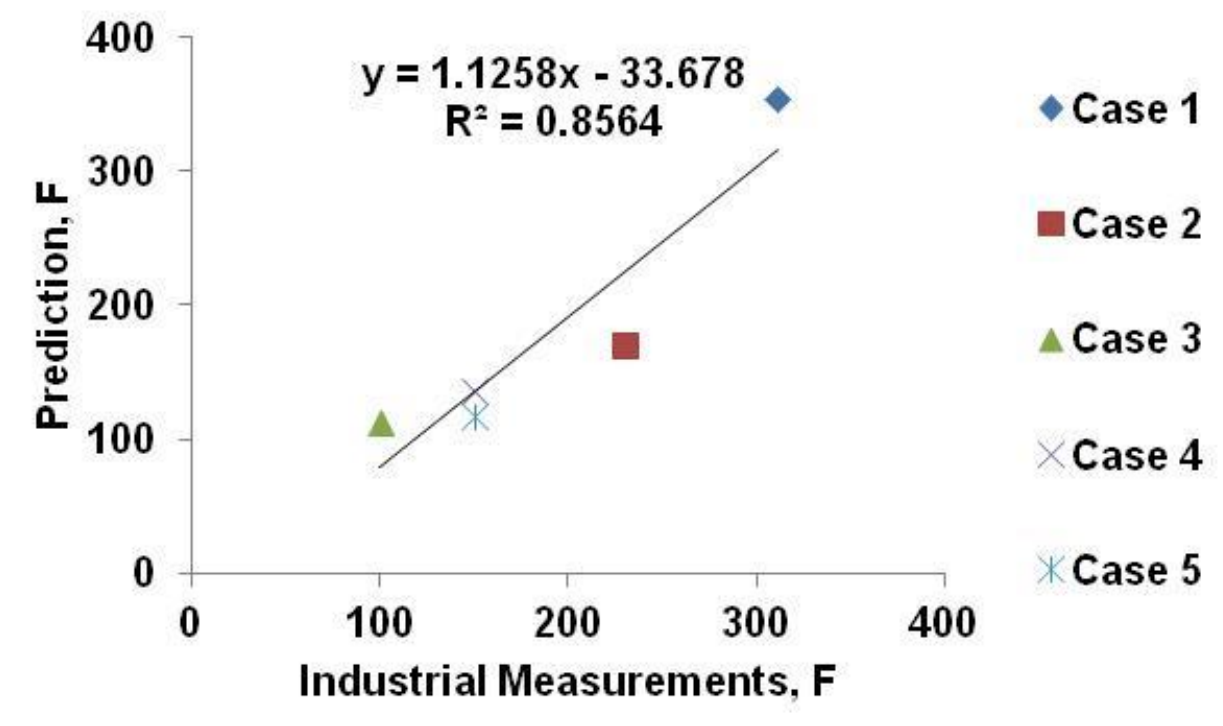

Figure 30 Validation of model by comparing predictions with industrial trials

\subsubsection{Excel-based calculator for ladles}

The spreadsheet model uses thermal properties based on selection of the type of lining. For 
advance users, the spreadsheet allows user defined property inputs. The outputs are generated automatically once all the inputs are provided. Figure 31a shows the interface of Web-based calculator. The spreadsheet calculates the temperature drop under the different possible conditions for melt handling for the same ladle and holding time. The spreadsheet can be used for process design and optimization with the goal of decreasing the tap temperature resulting in reduced energy consumption for melting steel. Figure $31 \mathrm{~b}$ shows an example of the difference in temperature drop under the various ladle conditions selected in the excel spreadsheet conditions in Figure 31a. From the predictions, the user could analyze the possible decrease in tap temperature for using a ladle cover or slag cover versus open top ladle.

\begin{tabular}{|c|c|c|}
\hline \multicolumn{3}{|l|}{ INPUTS } \\
\hline Ladle capacity & 11000 & $\mathrm{Ib}$ \\
\hline Tap temperature & 3100 & $F$ \\
\hline Preheat temperature & 1600 & $F$ \\
\hline Refractory & Alumina & \\
\hline Holding time & 10 & $\min$ \\
\hline Tap height & & $\mathrm{ft}$ \\
\hline Tap time & 2 & $\min$ \\
\hline Pouring Temperature & 2900 & $F$ \\
\hline \multicolumn{3}{|c|}{ OUTPUTS } \\
\hline Total temperature drop & 173 & $F$ \\
\hline Possible tap temperature & 3073 & $F$ \\
\hline Approximate savings & 15.48 & KWH \\
\hline
\end{tabular}

(a)

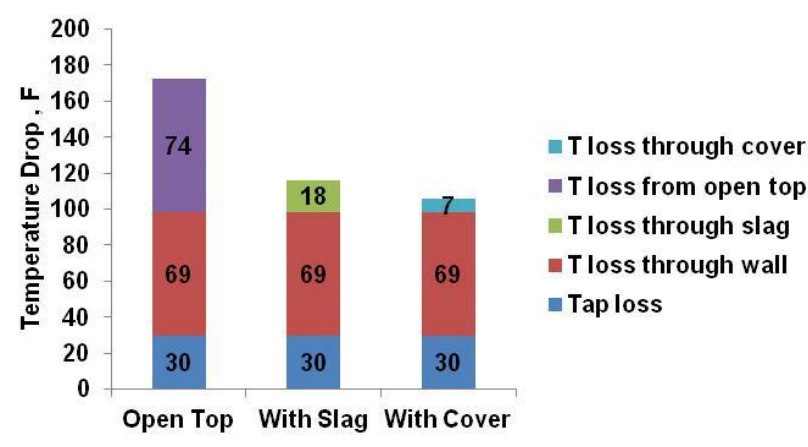

(b)

Figure 31 Interface of spreadsheet for calculating (a) temperature losses in ladle and (b) predicted temperature drop under different scenarios. Holding for 15 minutes in a 20 ton ladle lined with alumina refractory $(\mathrm{k}=1.5 \mathrm{~W} / \mathrm{m}-\mathrm{K})$ preheated to $1800 \mathrm{~F}$

\subsubsection{Development of model of energy use during melting in induction furnaces}

The model is an integrated heat balance with consideration of induction heating for increasing enthalpy during heating of steel charge, solid to liquid transition and sums the heat losses (fluxes $\left.F_{i}\right)$ :

$$
\int \sum_{i=2}^{i=5} F_{i} d t=m_{\text {scrap }}\left(C_{p}^{S}\left(T_{\text {melting }}-T_{\text {initial }}\right)+\Delta H_{\text {melting }}+C_{p}^{l}\left(T_{\text {tapping }}-T_{\text {melting }}\right)\right)
$$

During steel melting, Flux 1 includes the energy required to heat the scrap charge and any liquid heel from their initial temperatures $\left(T_{\text {initial }}\right)$ to tapping temperature $\left(T_{\text {tapping }}\right)$, considering all phase transformations $\left(\Delta H_{\text {melting }}\right)$. As shown in Figure 32 , the other Fluxes are heat losses $\left(F_{i}, \mathrm{~W} / \mathrm{m}^{2}\right)$ :

- Flux 2 - accumulation heat to lining,

- Flux 3 - to cooling water consisting of two parts:

Flux $3 \mathrm{a}$ - to compensate for Joule heating in the induction coil

Flux $3 b$ - heat conducted through lining

- Flux 4 and Flux 5 are radiation and convection losses from top melt surface. 


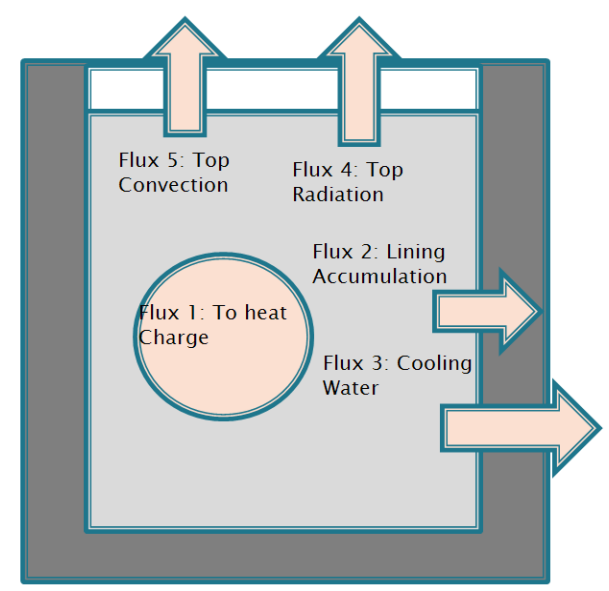

Figure 32 Heat fluxes considered in model of steel melting induction furnace

These fluxes can be divided into three unique periods during the operation of an induction furnace:

- period 1 (natural cooling) from previous tap to power on

- $\quad$ period 2 (high power heating) from power on to to fully melted solid charge

- period 3 (low power heating) correction of liquid metal chemistry, temperature to tap.

The periods have different dominating heat transfer natures: period 1 and period 2 are dominated by unsteady state heat tranfer with heat transfer becoming closer to steady during period 3 (Figure 33).

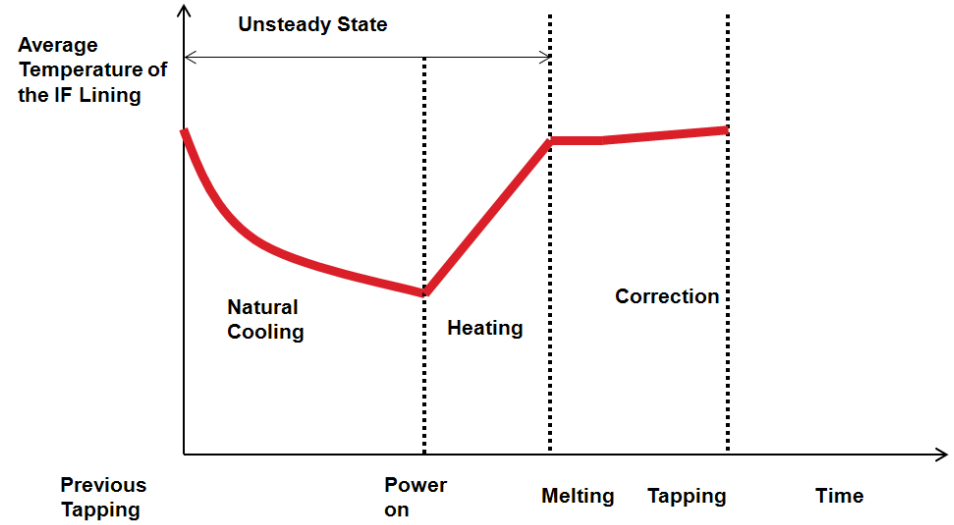

Figure 33 Temperature of lining during three periods of melting steel in induction furnace

Due to the nature of these periods, two different calculation approaches were used. In the first approach, unsteady state heat tranfer during periods 1 and 2 was modeled using Fluent CFD software for the real 3-D IF geometries of different capacities (Figure 34). In this calculation, the term "lining accumulation" refers to the heat accumulated in the furnace lining during heating periods 1 and 2. If the furnace is cold started, a considerable part of the energy is initially used to heat the furnace lining. If the furnace is hot started, the temperature of the furnace will decrease gradually after tap, which will influence heat accumulation in lining for the next heat. The shorter the time, the less energy consumption. Therefore, scheduling is an important factor with respect to energy savings in foundries. The mathematic expression for the regression of average lining temperature $\left(T_{\text {average, }}{ }^{0} C\right)$ versus time between previous tap and power on $(t$, min) for different furnace capacity $(C$, ton $)$ is: 


$$
T_{\text {average }}=20+590 e^{-0.008 \cdot t \cdot C^{-0.772}}
$$

Cooling water is used to protect lining and coils. Joule heat generated by the induction coils and heat transferred through the lining are transferred to the cooling water. The percentage of Joule heat losses depends on induction furnace design and capacity and was evaluated using industrial measurements in several foundries of the total electrical energy consumption. Another part of heat transferred to the cooling water is the heat conducted through the lining of the induction furnace. These heat losses were calculated assuming steady state heat transfer during period 3.

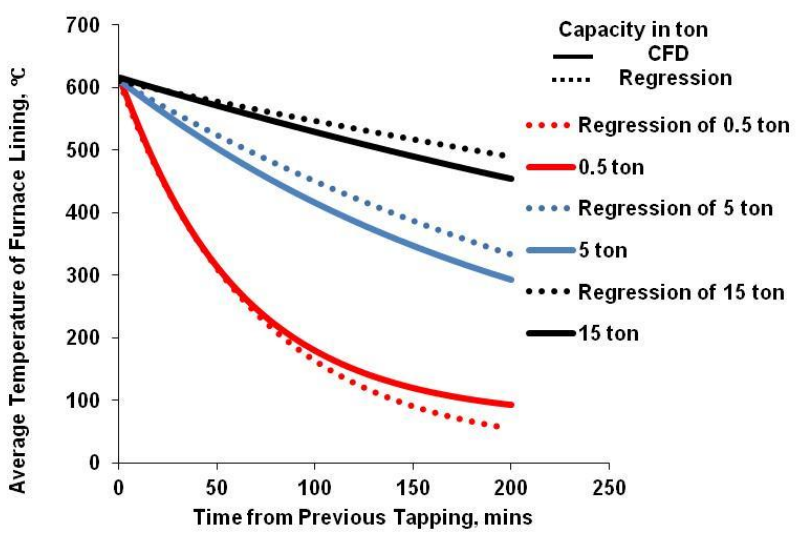

Figure 34 Temperature of IF lining between heats - Fluent model and regression analysis

Both radiation and convection heat losses were considered from the top of the furnace. Melting under a cover decreases the heat losses by radiation and convection. These effects were estimated using FLUENT CFD modeling and introduced into the EXCEL calculator as simplified in Equations 4 and 5 where emissivity $(\varepsilon)$ and the coefficient of heat transfer $(\alpha)$ were estimated from CFD calculations:

$$
\begin{aligned}
& \text { Flux } 4=\varepsilon \sigma\left(T_{\text {melt }}{ }^{4}-T_{0}{ }^{4}\right) A \\
& \text { Flux } 5=\alpha\left(T_{\text {melt }}-T_{0}\right) A
\end{aligned}
$$

Melting efficiency can be affected by several factors including hot versus cold lining and preheated scrap or a liquid heel from the previous heat. The possible effects of these differing scenarios on process time and energy consumption are shown in Figure 35. For example, scrap preheating can decrease the electrical energy consumption while simultaneously accelerating furnace productivity. 


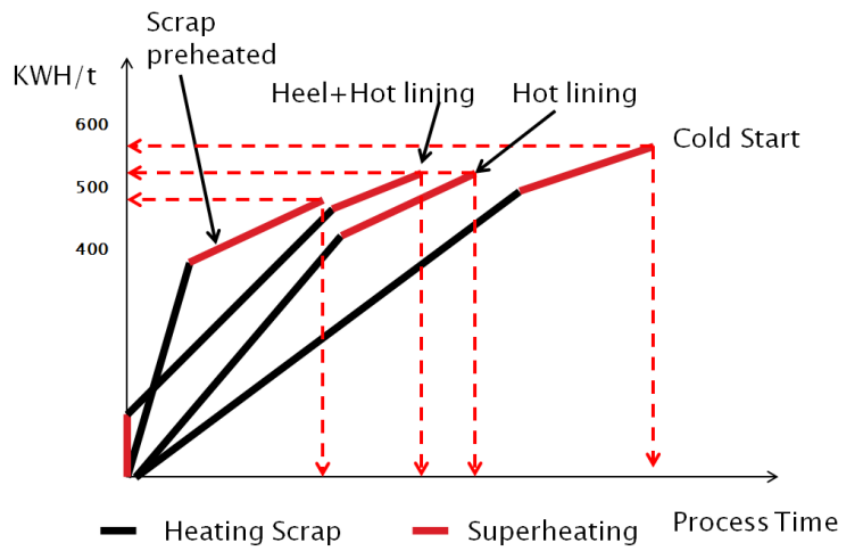

Figure 35 Illustration of effects of melting practice on process time and energy consumption

\subsubsection{Excel-based electrical energy consumption calculator/optimizer}

Based on the equations and approximations described above, an excel-based spreadsheet calculator was developed. The interface of the calculator is shown in Figure 36. It can be divided into four parts: input, output, optimization and graphical results. Necessary parameters are entered, such as furnace geometry, power supply, temperature data, operation schedule, type of charge, etc. Based on the input parameters, the calculation is completed and the results are directly shown in the output column. The specific power distribution is shown in the graph.

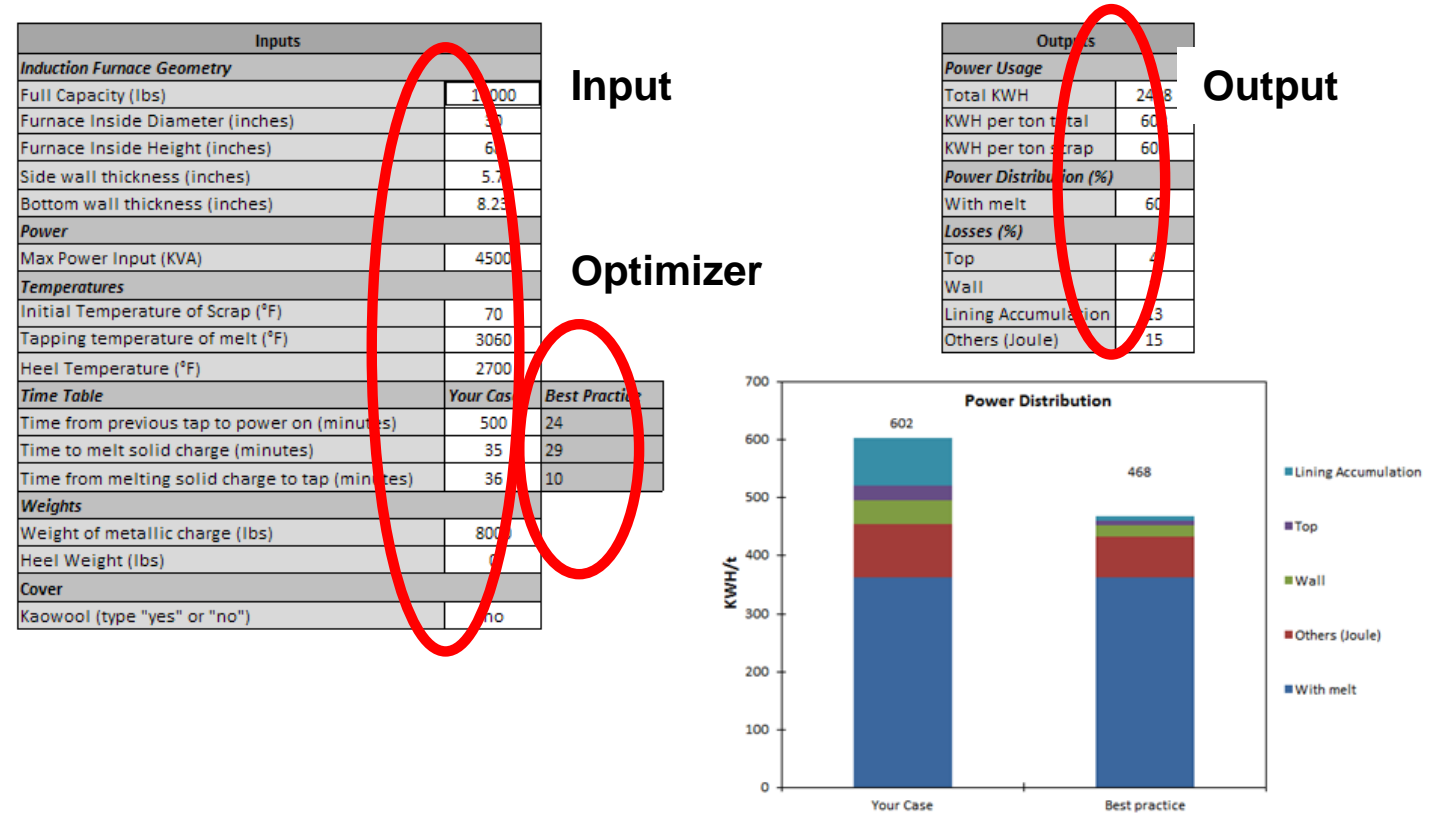

Figure 36 Interface of spreadsheet calculator for IF energy consumption

Best practices are considered as possible ways of minimizing electrical energy consumption. With maximum power supply known, minimum melting time can be determined. The minimum correction time can also be determined from industry best practices. The value is usually proportional to the furnace's capacity. Using the best practice minimum melting and correction time, the calculator can estimated the adjusted energy consumption. After several iterations, the minimum electrical energy consumption can be determined. 


\subsubsection{Validation of the induction furnace spreadsheet calculator}

Results from previous industrial trials in three induction furnace foundries with various furnace capacities were used for model validation. The measured results were compared with model calculations (Figure 37) showing excellent agreement.

Table 13 illustrates the model predictions and measured results based on the effects of different melting practices in $9000 \mathrm{lb}$ capacity IF on furnace productivity and electrical energy consumption. Optimization of melting practice will allow foundry to decrease energy consumption by up to $20-30 \%$ with up to a $50 \%$ increase in furnace productivity.

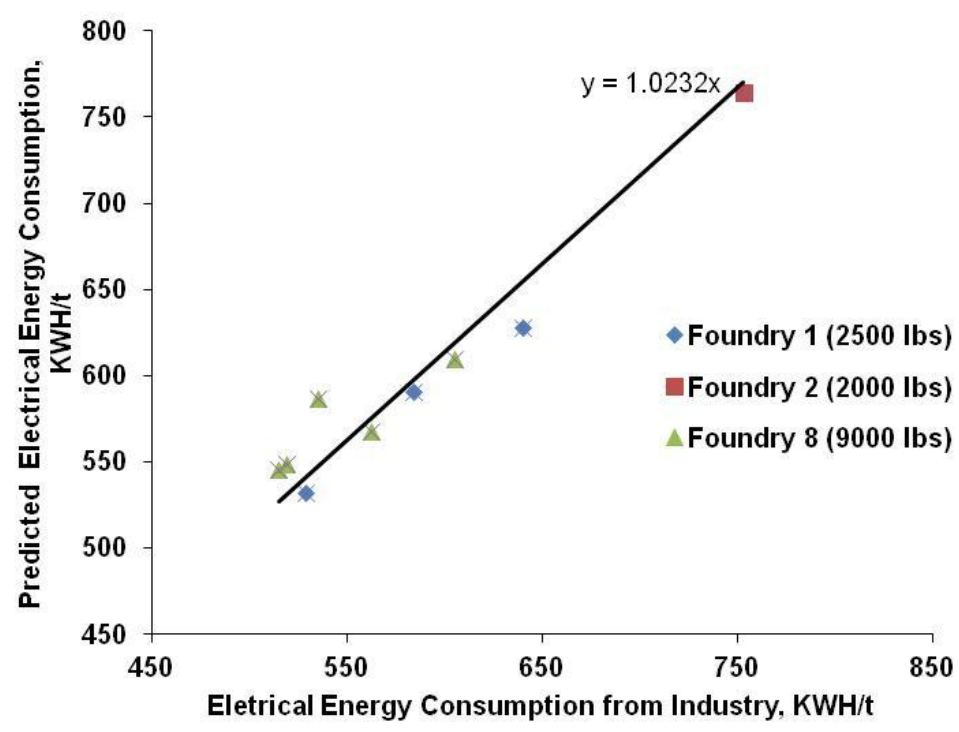

Figure 37 Validation of model with induction furnace electrical energy consumption data

Table 13 Comparing industrial results and induction furnace model - best practice optimization

\begin{tabular}{|l|l|l|l|l|}
\hline Practices & $\begin{array}{l}\text { Time from previous } \\
\text { tap, min }\end{array}$ & $\begin{array}{l}\text { Melting time, } \\
\text { min }\end{array}$ & $\begin{array}{l}\text { Holding time, } \\
\text { min }\end{array}$ & kWh/ton \\
\hline $\begin{array}{l}\text { Industrial case: } \\
\text {-measured }\end{array}$ & $\begin{array}{l}\text { Cold start } \\
\text {-calculated }\end{array}$ & 34 & 36 & 640 \\
\hline $\begin{array}{l}\text { Optimized cases: } \\
\text {-hot lining }\end{array}$ & 24 & 36 & 628 \\
-gas preheated charge & 24 & 31 & 10 & 466 \\
\hline
\end{tabular}

\section{Benefits Assessment}

The industrial trials proved that energy optimization in induction furnaces could save between 5 and $15 \%$ in the melting operation from improvements in scheduling and improved melting practices. The industrial trials showed that in electric arc furnace operations the use of chemical energy saved between 6 and 15\% electrical energy consumption. Improved ladle operations showed that the tapping temperature could be reduced by 50 to $100^{\circ} \mathrm{F}$ which saves an additional $3-5 \%$ electrical energy. By combining furnace and ladle improvements, potential savings are between 10 and 20\% for all induction and electric arc furnace foundries. Many companies have already implemented some of the changes and in some foundries all of the improvements. 
This task was predicted to result in an average energy savings of 2.3 trillion BTU's/year over a 10 year period. Current (2012) annual energy saving estimates, based on dissemination to the casting industry in 2012 and market penetration of $90 \%$ by 2022, is 2.7 trillion BTU's/year (Appendix 1).

Because the primary energy associated with melting in steel foundries is electricity, the direct reduction of $6-20 \%$ of the electrical power in melting reduced the greenhouse gas emissions associated with generating and transmitting the electrical energy. Implementation of the technology will also result in a reduction of environmental emissions associated with the melting and pouring of the steel. The average annual estimate of CO2 reduction per year through 2022 is 0.048 Million Metric Tons of Carbon Equivalent (MM TCE) based on the energy savings above.

\section{Commercialization}

The technologies developed in this project are commercially available and have already been implemented in part or whole by several industrial foundries (full summary results in conclusions). Barriers to the implementation are age of equipment (many furnaces over 50 years old) and lack of capital to make improvements (electrical controls, oxy-fuel burners, etc.). Most of the companies that have made substantial energy improvements were able to update their equipment and controls.

\section{Accomplishments}

All of the six tasks were completed with several industrial trials to prove the energy improvements through implementing the technologies developed through this program. There have been 12 publications and 5 graduate students that reflect the work from this project:

\subsection{Publications}

1. Peaslee, K.D., Biswas, S., Lekakh, S., and He, J., "Steel Foundry Melting Energy Efficiency Progress," $66^{\text {th }}$ Technical and Operating Conference, SFSA, Chicago, December, 2012 (submitted).

2. Biswas, S., Peaslee, K.D., and Lekakh, S., "Increasing Melting Energy Efficiency in Steel Foundries," AFS Conference Proceedings, 2012, Paper 12-040.

3. Biswas, S., Lekakh, S., and Peaslee, K.D., "Reducing Tap Temperatures to Minimize Energy Use in Melting," $65^{\text {th }}$ Technical and Operating Conference, SFSA, Chicago, December, 2011.

4. Peaslee, K., Lekakh, S. and Martinez, E., "Improvements in Steel Melting Efficiency Industrial Trials," $62^{\text {nd }}$ Technical and Operating Conference, Paper 1.3, SFSA, Chicago, IL, Dec. 2008.

5. Monroe, R., Peaslee, K. and Eppich, R., "Energy Efficiency in Steel Casting Production," $62^{\text {nd }}$ Technical and Operating Conference, Paper 5.9, SFSA, Chicago, IL, Dec. 2008.

6. Peaslee, K.D., Lekakh, S.N., Smith, J.D., Vibhandik, M., "Increasing Energy Efficiency through Improvements in Ladle Materials and Practices, 61st Technical and Operating Conference, SFSA, 2007.

7. Peaslee, K.D, Lekakh, S.N., Richards, V.L., Carpenter, J.D. and Wang, C., "Decreasing Electrical Energy Consumption through SiC Additions," 60th Technical and Operating Conference Proceedings, SFSA, 2006, Paper 3.4, pp. 1-14. 
8. Peaslee, K.D., Lekakh, S.N., Smith, J.D., Vibhandik, M., "Improving Melting Efficiency through the Application of New Refractory Materials," 60th Technical and Operating Conference Proceedings, SFSA, 2006, Paper 3.5, pp. 1-14.

9. Peaslee, K., Lekakh, S., Sander, T. and Smith, J., "Efficiency in Steel Melting: Ladle Developments," 59th Technical and Operating Conference Proceedings, SFSA, 2005, Paper 4.2, 1-11.

10. Peaslee, K., Lekakh, S., Richards, V. and Triplett, J., "Efficiency in Steel Melting: Opportunities and Progress," 59th Technical and Operating Conference Proceedings, SFSA, 2005, Paper 4.7, 1-16.

11. Peaslee, K.D., Webber, D.S., Lekakh, S., and Randall, B., "Recovery and Chemistry Control in Steel Melting," $58^{\text {th }}$ Technical and Operating Conf. Proc., SFSA, 2004, paper 4.1, pp. 1-13.

12. Peaslee, K.D., Lekakh, S., and Randall, B., "Thermal Efficiency of Steel Melting," 58th Technical and Operating Conf. Proc., SFSA, 2004, paper 4.7, pp. 1-22.

\subsection{Graduate students thesis based on the project work}

1. Siddhartha Biswas, M.S., "Energy Efficiency in Metals Processing," 2012.

2. Darryl Webber, Ph.D., "Alloy Dissolution in Argon Stirred Steel," 2011 (partially).

3. $\quad$ Edith Martinez, M.S., "Calcium Wire Ladle Treatment to Improve Cleanliness of Centrifugally Cast Steel," 2011 (partially).

4. Phanikrishna Angara, M.S., "Recovery of Materials from Recycling of Spent Furnace Linings," 2008 (partially).

5. Mangesh Vibhandik, M.S., "The Effects of Highly Porous Refractory Materials on Steel Ladle Heat Loss," 2008.

\subsection{Invited Presentations:}

1. "Saving Energy in Melting: Tips and Ideas for Foundries," AFS Birmingham Chapter Meeting, Birmingham, AL, March 8, 2010.

2. "Improving Thermal Efficiency in Melting and Ladles," International Iron and Melting Conference, American Foundry Society, Orlando, Florida, January 21, 2009.

\section{Summary and Conclusions}

In summary, the following was concluded from the research project:

- $\quad$ Electrical energy can be reduced during melting in induction furnaces by an average of $15 \%$ on the first heat of production through improved preheating practices. Electrical energy was reduced by $5-10 \%$ on heats melted in hot linings through practice improvements (covers).

- Changing the melting practices to implement changes to minimize alloys added to the charge, more consistently chemical sampling, and avoiding adding alloys through slag resulted in improvements in Mn recovery and improved consistency. In one industrial trial, the change represents a $20 \%$ decrease in the Mn alloys added to make the same grade as before the changes.

- Industrial trials showed a noticeable decrease in electrical consumption with the addition of chemical energy provided by $\mathrm{SiC}$ additions in an EAF. The electrical energy decrease was $8 \%$ when $\mathrm{SiC}$ was the primary agent of chemical energy. Productivity also increased by $6 \%$. In the trials in which there were multiple chemical energy sources (SiC plus oxy-fuel burners) the energy decrease due to the $\mathrm{SiC}$ was less $(\sim 5 \%)$ and the 
productivity increase was insignificant. Other melting improvements were a direct result of the $\mathrm{SiC}$ addition including a lowering of the start temperature for oxygen boiling, decrease in the lining erosion, increase in the lifetime of refractory roofs, and safer (less violent) oxygen boiling.

- Industrial trials using chemical energy in the form of a door oxy-fuel burner and sidewall Co-Jet in an EAF resulted in decreased average electrical consumption by 49 $\mathrm{kWh} / \mathrm{t}(10 \%)$. Heats with no delays were consistently low in energy consumption (between 400 and $420 \mathrm{kWh} / \mathrm{t}$ ) indicating potential savings of $20 \%$ with chemical energy with more efficient scheduling and preventive maintenance to avoid delays in the furnace. Melt-down time (time from first power on until the scrap was completely melted $=$ flat bath) was decreased by $15 \%$ with the addition of the oxy-fuel and Co-Jet. There is potential for up to a $30 \%$ decrease in the melting time based on the typical times measured during heats observed during the industrial trials. The average total heat time decreased by 22 minutes $(15 \%)$ when using the oxy-fuel/Co-Jet practice. There is potential for significant additional heat time savings based on one of the trial heats in which the total heat time was 110 minutes, nearly $40 \%$ less than the average time before the oxy-fuel Co-Jet installation.

- Industrial trials with low lower thermal conductivity "sandwich" linings resulted in a reduced tap temperature of $60^{\circ} \mathrm{F}$ from standard castable ladles, a reduction in melting energy by $3 \%$. The energy loss through the sidewalls is reduced by $40 \%$ with the sandwich lining when compared to common alumina castable linings.

- $\quad$ Two Excel spreadsheet models were completed to estimate energy consumption and optimize minimum practical energy use in induction furnace melting and ladle transport to pouring molds.

An online survey was sent to steel foundries to document improvements made since the project started in 2004. Fifteen foundries participated in the survey. Among the participating foundries in 2012, they operate 60 furnaces in total (22 EAFs \& 38 IFs). The comparison in number foundries and furnaces participating in previous survey in 2004 and the latest survey in 2012 is shown in Figure 38.

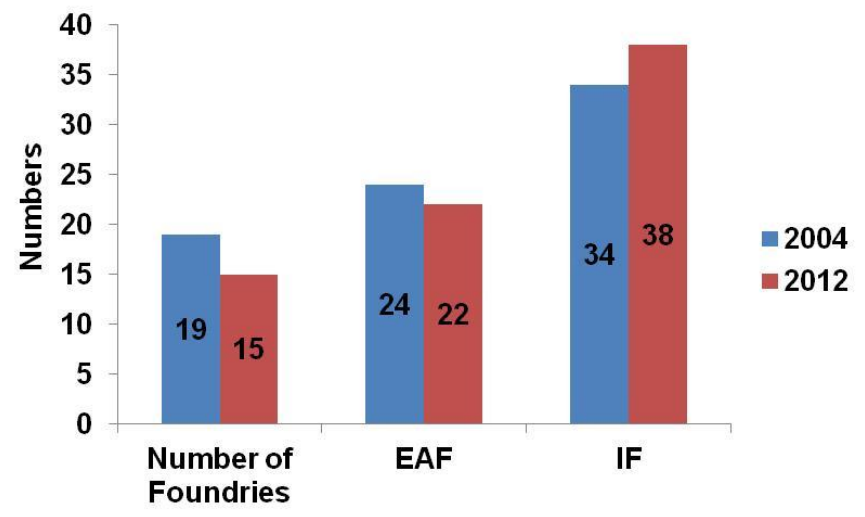

Figure 38: Comparison of participating foundries and furnaces (EAF \& IF) in 2004 (start of project) and 2012 (end of project).

One of the recommended areas of improvement at the beginning of the research was electrical consumption meters and controls. Today, all foundry EAFs have power monitoring devices installed compared to only $38 \%$ in 2004 (see Figure 38). Induction furnaces have only slightly 
improved.

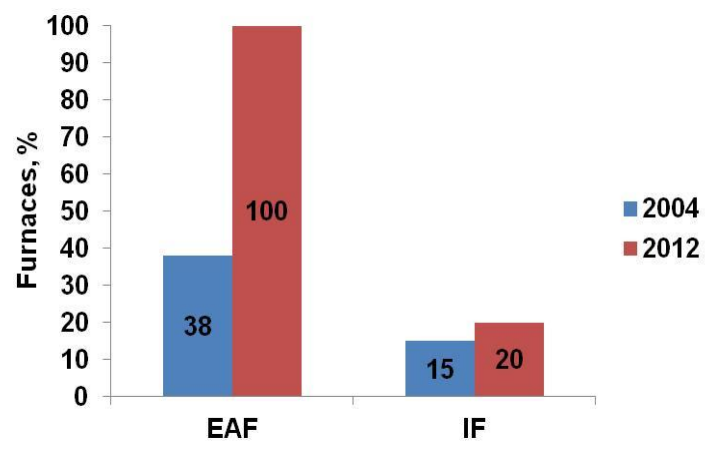

Figure 39: Power monitoring devices for EAFs and IFs in 2004 and 2012.

With more energy monitoring devices in foundries, the electrical energy consumed is more reliable and consistent in 2012 than at the beginning of the project (2004). The electrical power consumption has decreased by $7 \%$ from $527 \mathrm{kWh} /$ ton in 2004 to $491 \mathrm{kWh} /$ ton in 2012 (see Figure 39). This is a significant improvement because only about $50 \%$ of the foundries have implemented some of the changes recommended by this research. This would support the earlier conclusions that there is a potential for a $20 \%$ decrease in the electrical consumption if all of the foundries implemented all of the improvements.

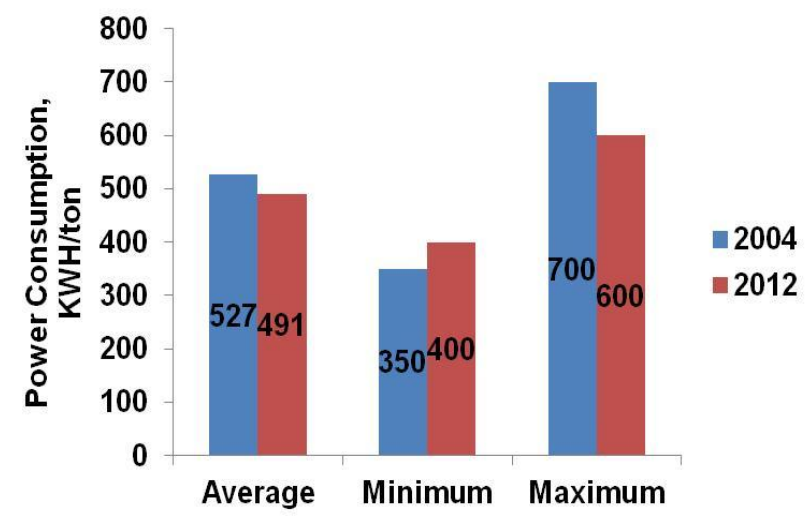

Figure 40: Electrical power consumption at the beginning (2004) and end (2012) of project.

\section{References}

1. J. Stubbles, Energy Use in the U.S. Steel Industry: An Historical Perspective and Future Opportunities, Energetics, 2000.

2. Sismanis, P.G.; Argyropoulos, S. A.; The Effect of Oxygen on the Recovery and Dissolution of Ferroalloys Proceedings of the 69th Steelmaking Conference, Vol. 69 (1986), pp. 315-326.

3. Tanaka, M.; Mazumdar, D.; Guthrie, R.I.L.; Motions of Alloying Additions During Furnace Tapping in Steelmaking Processing Operations Metallurgical Transactions B: Process Metallurgy (1993), Vol. 24B, No.4, p. 647.

4. Berg, H.; Laux, H.; Johansen, S. T.; Klevan, O. S.; Flow Pattern and Alloy Dissolution During Tapping of Steel Furnaces Ironmaking and Steelmaking, Vol. 26 (1999), No. 2, pp. 127-139. 
5. Schade, J.; Argyropoulus, S. A.; Mclean, A.; Cored-Wire Microexothermic Alloys for Tundish Metallurgy Transactions of the Iron and Steel Society, Vol. 12 (1991), pp. 1931.

6. Biswas, S., Lekakh, S., and Peaslee, K.D., "Reducing Tap Temperatures to Minimize Energy Use in Melting," 65th Technical and Operating Conference, SFSA, Chicago, December, 2011. 


\section{Appendix 1: Assumptions for Calculating Energy Savings}

- According to the Department of Commerce, 1.1 million tons of steel castings are shipped per year average (Shipment data from 1996-2002). Energy use for the steel foundry industry was computed based on 1.1 million tons of total castings shipped, and was put on a per unit basis assuming a market of 100 foundries. This is approximately the number of foundries that generate most of the production tonnage, and also means that the per-unit impact computed in this spreadsheet affects $1 \%$ of the yearly production for the steel foundry industry.

- A majority of ferrous castings are made from scrap. The average scrap price was $\$ 88$ per ton (Source: U.S. Geological Survey, Mineral Commodity Summaries, Jan 2004)

- Estimated market growth rate for steel castings is $0.8 \%$ (AFS Metalcasting Forecast \& Trends 2002 (Oct. 2001)).

- The Commercial Introduction without with support is based on information from SFSA, who have said that there would be a 25 year delay in this project without DOE funding.

- Annual market growth rate: $0.8 \%$ (AFS Metalcasting Forecast \& Trends)

- Ultimate Potential Accessible Market: $90 \%$

- Likely Technology Market Share: $80 \%$

- Savings Attributed to Program: $100 \%$ 